Article

\title{
Therapeutic Effects of Bee Bread on Obesity-Induced Testicular-Derived Oxidative Stress, Inflammation, and Apoptosis in High-Fat Diet Obese Rat Model
}

\author{
Joseph Bagi Suleiman ${ }^{1,2} \mathbb{D}$, Mahaneem Mohamed ${ }^{1,3, *(\mathbb{D}}$, Ainul Bahiyah Abu Bakar ${ }^{1}$, Zaida Zakaria ${ }^{1}$, \\ Zaidatul Akmal Othman ${ }^{1,4}$ (D) and Victor Udo Nna ${ }^{5}$
}

Citation: Suleiman, J.B.; Mohamed, M.; Abu Bakar, A.B.; Zakaria, Z.; Othman, Z.A.; Nna, V.U. Therapeutic Effects of Bee Bread on ObesityInduced Testicular-Derived Oxidative Stress, Inflammation, and Apoptosis in High-Fat Diet Obese Rat Model. Antioxidants 2022, 11, 255. https://doi.org/10.3390/ antiox 11020255

Academic Editors: Valéria Cristina Sandrim and Priscila Rezeck Nunes

Received: 29 December 2021

Accepted: 25 January 2022

Published: 28 January 2022

Publisher's Note: MDPI stays neutral with regard to jurisdictional claims in published maps and institutional affiliations.

Copyright: (C) 2022 by the authors. Licensee MDPI, Basel, Switzerland. This article is an open access article distributed under the terms and conditions of the Creative Commons Attribution (CC BY) license (https:// creativecommons.org/licenses/by/ $4.0 /)$.

1 Department of Physiology, School of Medical Sciences, Universiti Sains Malaysia, Kubang Kerian 16150, Kelantan, Malaysia; bagisuleiman@student.usm.my (J.B.S.); ainul@usm.my (A.B.A.B.); zaida_zakaria@student.usm.my (Z.Z.); zaidaakmal@unisza.edu.my (Z.A.O.)

2 Department of Science Laboratory Technology, Akanu Ibiam Federal Polytechnic, Unwana P.O. Box 1007, Ebonyi State, Nigeria

3 Unit of Integrative Medicine, School of Medical Sciences, Universiti Sains Malaysia, Kubang Kerian 16150, Kelantan, Malaysia

4 Unit of Physiology, Faculty of Medicine, Universiti Sultan Zainal Abidin, Kuala Terengganu 20400, Terengganu, Malaysia

5 Department of Physiology, Faculty of Basic Medical Sciences, College of Medical Sciences, University of Calabar, Calabar P.O. Box 1115, Cross River State, Nigeria; victorudon@unical.edu.ng

* Correspondence: mahaneem@usm.my

Abstract: Obesity is a debilitating disorder with a variety of problems including oxidative stress, inflammation, and apoptosis. The aim of our study was to investigate the therapeutic role of bee bread on oxidative stress, apoptosis, and inflammation in the testis of obese rats. Thirty-two adult male Sprague Dawley rats, with weights between 230-300 g, were distributed into four groups ( $\mathrm{n}=8$ /group), namely normal control $(\mathrm{C})$, obese $(\mathrm{Ob})$, obese $+\mathrm{BB}$ or obese + OR [high-fat diet (HFD) for 6 weeks then HFD plus bee bread or orlistat for another 6 weeks] groups. Bee bread $(0.5 \mathrm{~g} / \mathrm{kg})$ or orlistat $(10 \mathrm{mg} / \mathrm{kg} /$ day $)$ was diluted with distilled water and administered daily for 6 weeks by oral gavage. There were significant decreases in the activities of antioxidant enzymes [glutathione-S-transferase (GST), superoxide dismutase (SOD), glutathione peroxidase (GPx), catalase (CAT), glutathione reductase (GR)], glutathione (GSH)] and total antioxidant capacity (TAC) levels and mRNA expressions of nuclear factor erythroid 2-related factor 2 (Nrf2), superoxide dismutase $(\mathrm{Sod})$, catalase (Cat) and glutathione peroxidase $(G p x)$ in the obese group relative to the control group. Meanwhile, the mRNA levels of pro-inflammatory markers, namely: inducible nitric oxide synthase (Inos), nuclear factor kappa B (Nf- $\kappa \beta)$, tumour necrotic factor $\alpha(\operatorname{Tnf}-\alpha)$ and interleukin $1 \beta(I l-1 \beta)$ were significantly increased while interleukin (Il-10) was decreased in the obese group relative to the control group. Further, proliferating cell nuclear antigen (PCNA) immunoexpressions decreased while cleaved caspase-3 immunohistochemical staining increased significantly in the obese group, in addition to increases in the mRNA levels of p53, Bax, Caspases-8, 9 and 3, relative to the control group. Treatment with bee bread showed increases in antioxidant enzymes and PCNA immunoexpression, as well as decreases in inflammation and apoptosis markers in the testes. This study has shown that bee bread has therapeutic effects against oxidative stress, inflammation, apoptosis in the testis of HFD-induced obese male rats, thereby suggesting its role as a natural supplement capable of treating obesity-induced male reproductive impairment.

Keywords: oxidative stress; inflammation; apoptosis; bee bread; testis

\section{Introduction}

Bee bread is usually formed due to the outcome of the fermentation from the combination of pollen, digestive enzymes found in saliva, and nectar [1,2]. It possesses high 
protein, carbohydrates, fats, and mineral components. Bee bread comprises of $24-35 \%$ carbohydrates, 20\% protein, 3\% lipids, 3\% minerals and vitamins, enzymes (phosphatases, glucose-oxidase, saccharase and amylase), amino acids (proline, glutamic acid, aspartic acid, histidine, arginine, valine, isoleucine, leucine, methionine, tryptophan, lysine, threonine, cysteine, phenylalanine, alanine, glycine, tyrosine and serine), carotenoids, phenolic acid and flavonoids, pantothenic acid, polyphenols, and sterols [3]. The possession of large amounts of protein and amino acid is due to the fact that bee pollen also possesses a high amount of these nutrients. It has also been found that the amount of protein in bee bread depends largely on the type of flower, pollen grains and region where they are located [3]. The presence of phenolic acids (caffeic acid, gallic acid, trans 3-hydroxycinnamic acid, transferulic acid, 2-hydroxycinnamic acid) and flavonoids (apigenin, kaempferol, quercetin, and mangiferin) have been found in our study [3].

Bee bread also has several health benefits including antioxidant [4,5], antiinflammatory [6], anti-apoptotic [7], antimicrobial [3,8], anticancer [9], and immunological effects $[10,11]$ on various tissues. Its effects on the male reproductive system cannot be over emphasised; our previous study has revealed that concurrent administration of a high-fat diet and $0.5 \mathrm{~g} / \mathrm{kg}$ bee bread for twelve weeks showed protective effects against testicular oxidative stress, inflammation, and apoptosis in rats [12].

Obesity is defined as a combination of various factors (oxidative stress, inflammation, and apoptosis) giving rise to increased levels of fat in the body which results in a disease with detrimental consequences, such as hypertension, high LDL cholesterol, low HDL cholesterol, or dyslipidemia, Type 2 diabetes, coronary heart disease, stroke, gallbladder disease, Osteoarthritis, and even mortality [13]. The prevalence of obesity has reached a pandemic level in the last 50 years $[14,15]$. The serious detrimental effects of obesity have been seen on the brain [16], thyroid gland [17], heart [18], kidneys [19], liver [20], pancreas [21], spleen [22], skeletal muscles [23], bones [24], female reductive system [25] and the male reproductive system [26].

Oxidative stress evolves from the excessive production of the radical oxygen species (ROS) as a result of the imbalance between its production and elimination by the antioxidant system. The radical oxygen reactive species (ROS) includes a hydroxyl ion $\left(\mathrm{OH}^{-}\right)$, hydrogen peroxide $\left(\mathrm{H}_{2} \mathrm{O}_{2}\right)$ and a superoxide anion $\left(\mathrm{O}_{2}^{-}\right)$. During obesity, oxidative stress in the testis of males is heightened, as seen in both clinical [27,28] and experimental studies [29-31]. Likewise, inflammation plays a role in testicular dysfunction because of the imbalance between the pro-inflammatory and anti-inflammatory cytokines [32]. It has been implicated in the testis of most patients with metabolic diseases such as obesity [26]

Apoptosis as a process of programmed cell death has been studied in detail in the past, especially in the testis where about $75 \%$ of the germ cells are eliminated via the process. The process of apoptosis is irreversible with the activation of caspase, and a cell is committed to death while the engulfment genes remove the dead cell. It is important to note that the precise mechanisms of male germ cell apoptosis is yet to be established because of the web of interactions of different types of cells within the testis and their ability to respond to stimuli $[33,34]$.

Therefore, the motive of this study was to examine the possible therapeutic effects of bee bread on oxidative stress, inflammation, and apoptosis in the testis of obese rats, whereby rats were fed with a high-fat diet (HFD) for 6 weeks to induce obesity and then treated with bee bread for another 6 weeks.

\section{Materials and Methods}

\subsection{Animal Handling}

Male Sprague Dawley rats, aged 10 weeks old, measuring between 230 and 300 g, all 32 in number, were procured from the Animal Research and Service Centre (ARASC), Universiti Sains Malaysia (USM), Kelantan, Malaysia. The rats were brought to the laboratory of the Department of Physiology, School of Medical Sciences, USM, Malaysia and kept in animal room with 12/12-h reversed light/dark cycle and photoperiods at 12:00 p.m. to 
12:00 a.m., and the temperature was regulated at $23 \pm 2{ }^{\circ} \mathrm{C}$. Just before the start of the study, rats were acclimatised for 1 week. Meanwhile, animals were allowed free access to rat pellets or HFD and water. Ethical approval (USM/IACUC/2018/(113)(933) was issued by USM Animal Ethics Committee. Instructions on animal handling and care were strictly followed according to the National Institute of Health.

\subsection{Materials}

\subsubsection{Preparation of Bee Bread Samples}

Fresh bee bread, obtained from Heterotrigona itama stingless bees, was bought from Mentari Technobee PLT (bee farm) in Kota Bharu, Kelantan, the East coast region of Malaysia, south-east Asia. It was gathered from the month of January to March, which corresponds to the dry season in Malaysia. However, the bee bread was taken to the Physiology Laboratory, USM, Malaysia, and the initial weight was documented. Thereafter, the final weight was also determined after samples were dehydrated with the aid of a food dehydrator at $35^{\circ} \mathrm{C}$ for $4 \mathrm{~h}$ until no more change in weight was observed. They were then blended into powder form and stored at $-20{ }^{\circ} \mathrm{C}$ until use.

\subsubsection{Diets}

Standard rat pellets were bought from ARASC, USM, its constituents were $19.2 \%$ protein, $6.1 \%$ carbohydrate, $4.1 \%$ fat, $6.9 \%$ ash, $35.9 \%$ polysaccharides, $11.3 \%$ moisture, $4.9 \%$ disaccharides, trace elements, vitamins, minerals, amino acid, while the HFD was prepared following methods described by Othman et al. [35], which was made up of $300 \mathrm{mg}$ calcium, $100 \mathrm{UI}$ vitamin D3, 12\% cholesterol, $32 \mathrm{~g}$ ghee, and $68 \mathrm{~g}$ of powered standard rat pellets.

\subsubsection{Chemicals and Kits}

SensiFAST SYBR Hi-ROX One-Step PCR kit (Bioline, London, UK) (BIO-73005), as well as RNAlater, Acridine orange, and agarose (Sigma-Aldrich, St. Louis, MO, USA). Innu-Prep RNA mini kit Analytik (Jena, Germany), primers (Integrated DNA Technologies, IDT, Selangor, Malaysia), PCR tubes and strips (Applied Biosystems, Life Technologies, Dongguan, China). Proliferating cell nuclear antigen (PCNA) (PAA591Mi01), caspase3 (PAA626Ra01), tumour necrosis factor-alpha (TNF- $\alpha$ ) (PAA133Ra01), nuclear factor kappa B (NF-kB) (PAB824Ra01), IL-1ß (PAA563Ra01), and IL-10 (PAA056Ra01) rabbit polyclonal primary antibodies, were obtained from Cloud-Clone (Cloud-Clone Corp, Katy, TX, USA), while Dako EnVisionTM System/HRP, Rb (DAB) for signal detection was obtained from Agilent Technologies, Inc. (Santa Clara, CA, United States of America). Orlistat was obtained from Catalent Australia Pty Ltd., Australia. Other chemicals like [Picric acid (Sigma, St. Louis, MO, USA), formaladehyde (Merck, Darmstadt, Germany), acetic acid (Leica biosystems, United States of America] used for Bouin's solution, paraffin (Thermo Scientific, Bremen Germany), Haris hematoxylin solution (Sigma-Aldrich, St. Louis, MO, United States of America) and alcohol (Merck, Darmstadt, Germany) were of analytical grade.

\subsection{Study Design}

The rats (males) were fixed into four groups randomly ( $\mathrm{n}=8$ /group) as stated below:

i. Normal Control (C) group: administered with normal rat pellets and distilled water (1 mL) once daily for 12 weeks.

ii. Ob group: administered with HFD and $1 \mathrm{~mL}$ distilled water once daily for 12 weeks.

iii. $\quad \mathrm{Ob}+\mathrm{BB}$ group: administered with HFD for 6 weeks and then HFD + bee bread $(0.5 \mathrm{~g} / \mathrm{kg}$ b.w./day) for another 6 weeks.

iv. $\quad \mathrm{Ob}+\mathrm{OR}$ group: administered with HFD for 6 weeks and then HFD + orlistat (10 mg/kg b.w./day) for another 6 weeks. 
Bee bread and orlistat [120 mg of the active ingredient: orlistat, and the inactive ingredients: sodium starch glycolate, microcrystalline cellulose, talc, povidone, and sodium lauryl sulphate (standard drug)] doses were selected based on our previous studies $[35,36]$.

\subsection{Bodyweight, Absolute and Relative Organ Weights}

Throughout the period of experiment, weights of rats were recorded every week and on the last day prior to sacrifice. Seminal vesicles, penis, prostate, testes, and epididymis (male reproductive organs) were detached, rinsed, and weighed. The relative weights were computed and presented as a proportion of the final bodyweight. Values for Lee obesity index were terminated at 315 while values for body mass index were terminated at $0.75 \mathrm{gcm}^{-2}$ [37-39].

\subsection{Determination of Anthropometrical and Nutritional Parameters}

After the expiration of 12 weeks experiment, abdominal circumference (AC) and thoracic circumference (TC) and naso-anal length (NAL) were measured with rats placed under anesthesia. The energy intake (Energy intake $=$ mean food consumption $\times$ dietary metabolisable energy), Lee obesity index (Lee obesity index $=\frac{3 \sqrt{\text { body weight }(\mathrm{g})}}{\text { NAL }(\mathrm{cm})} \times 1000$ ) and BMI $\left(\mathrm{BMI}=\frac{\text { body weight }(\mathrm{g})}{(\text { Length })^{2}(\mathrm{~cm})^{2}}\right)$, were computed using values obtained from NAL body weights, and food consumption.

\subsection{Sample Collection}

During sacrifice, the left testis was divided into two parts. Ten percent homogenate was prepared using one part after being immersed in Tris- $\mathrm{HCl}$ buffer ( $\mathrm{pH} 7.4$ ) and then centrifuging at $4000 \times g$ for $15 \mathrm{~min}$ at $4{ }^{\circ} \mathrm{C}$, whereas the other half was put in RNAlater and stored at $-80^{\circ} \mathrm{C}$ for future use. The right testis was also harvested for the histological study.

\subsection{Determination of Serum Lipid Parameters}

To determine lipid parameters, blood from the abdominal aorta was utilised. Briefly, a centrifuge tube containing blood was made to stand for $1 \mathrm{~h}$, after which the separation of serum was carried out using a centrifuge for $10 \mathrm{~min}$ at $1400 \times \mathrm{g}$. Total cholesterol (TC) was evaluated by enzymatic method [Equipment: ARCHITECT ci8200 System], while highdensity lipoprotein cholesterol (HDL-C) was evaluated by the elimination of chylomicron (CM) [Equipment-ARCHITECT ci8200 System]. Triglyceride by enzymatic methods of Glycerol Phosphate oxidase [Equipment-ARCHITECT c System and ARCHITECT c Triglyceride assay file] and direct calculation was employed to calculate LDL-C from above.

\subsection{Histopathology of the Testis}

After the sacrifice, Bouin's solution was used to preserve the detached right testis for $24 \mathrm{~h}$, meanwhile, different grades of alcohol $(70,95$ and 100\%) were used to dehydrate it and then placed in blocks of paraffin. The microtome was used to Section $5 \mu \mathrm{m}$ thickness of tissue, while hematoxylin and eosin ( $\mathrm{H} \& \mathrm{E})$ technique was used for the staining process. Slides were observed under a light microscope (Olympus BX41, Olympus Corporation, Tokyo, Japan), and quantitative data obtained from images were analysed using Image Analyser software (Soft Imaging System, VGA utilities version 3.67e, Tokyo, Japan) at a magnification of $\times 100$.

\subsection{Oxidative Stress Status of the Testis}

Oxidative stress status was determined by evaluating the aliquot of the left testis homogenate which was stored in $-80^{\circ} \mathrm{C}$ for the following parameters, glutathione-S-transferase (GST), glutathione peroxidase (GPx), malondialdehyde (MDA), total antioxidant capacity (TAC), superoxide dismutase (SOD), catalase (CAT), glutathione reductase (GR), and glutathione (GSH) level. Concisely, methods of Ohkawa et al. [40] were used to assess MDA levels, and methods of Koracevic et al. [41] were used to assess TAC. Meanwhile, the enzyme 
activities of SOD were evaluated by methods of Sun et al. [42], and CAT was evaluated by methods of Goth [43]. Further, enzyme activity of GPx was determined by methods as described by Paglia and Valentine [44], and GST was evaluated by methods of Habig et al. [45], respectively, while GR activity was evaluated by methods of Carlberg and Mannervik [46], and GSH activity was evaluated by methods of Annuk et al. [47]. Similarly, ELISA kit (Elabscience, United States of America, Catalog No: E-EL-R0520) was used to evaluate inducible nitric oxide synthase (iNOS) activity and the total protein assay kit (Elabscience, United States of America, Catalog No: E-EL-R0520) was used to evaluate total protein level.

\subsection{Evaluation of Intratesticular Levels of Lactate, Lactate Dehydrogenase and Glucose}

Following manufacturer's instructions, the evaluation of lactate, lactate dehydrogenase and glucose levels were carried out with the aid of ELISA kits (Elabscience, USA), available commercially.

\subsection{RNA Expression for Antioxidant, Inflammatory and Apoptosis Markers}

\subsubsection{Extraction, Quality, and Purity of RNA}

Based on the maker's instructions, total RNA was evaluated using Innu Prep RNA mini kit (Analytik Jena, Jena, Germany). Similarly, twenty mg of testis tissue was used to determine the purity and concentration of samples with the aid of spectrophotometer (Eppendorf Nanodrop BioPhotometer plus, Stevenage, United Kingdom). Samples with OD of 260/280 and 1.8-2.0 were used to know samples without impurities. Meanwhile, samples that were pure were exposed to gel electrophoresis with application of $1 \%$ agarose $(w / v)$ in $1 \times$ LB buffer and observed with the aid of a UV transilluminator (ChemiDoc XRS, Bio-Rad Laboratories, Hercules, CA, USA), and pure samples were employed during the RT-qPCR amplification.

\subsubsection{Real-Time RT-qPCR}

RT-qPCR was evaluated using the StepOnePlus Real-Time PCR system (Applied Biosystems Co., Foster City, CA, USA) based on manufacturer's protocol. The melt curve and standard curve were used to determine their specificity and efficiencies after Integrated DNA Technologies (IDT, Malaysia) combined primers were selected from the gene bank (Table 1). Further, the 3-step cycling was conducted using the PCR machine [SensiFAST SYBR Hi-Rox One-Step PCR kit (Bioline, United Kingdom)]. Briefly, initial denaturation finished at $95{ }^{\circ} \mathrm{C}$ for $2 \mathrm{~min}$, then 40 cycles of denaturation for $5 \mathrm{~s}$ at $95{ }^{\circ} \mathrm{C}$, followed by annealing for $10 \mathrm{~s}$ at $60{ }^{\circ} \mathrm{C}$, and extension for $5 \mathrm{~s}$ at $72{ }^{\circ} \mathrm{C}$. A housekeeping gene [Glyceraldehyde-3-phosphate dehydrogenase (GAPDH)] was utilised, while the $2^{\triangle \mathrm{DDCt}}$ method was used for relative quantification [48].

Table 1. Sequence for Primers in tabular form.

\begin{tabular}{cccc}
\hline & & \multicolumn{2}{c}{ Primer Sequence (5'-3') } \\
\hline Gene & Accession Number & Forward & Reverse \\
\hline CAT & NM_012520.2 & ACAACTCCCAGAAGCCTAAGAATG & GCTTTTCCCTTGGCAGCTATG \\
Caspase-8 & NM_022277.1 & GTTCTCTCAGTTGCCTTCTCC & GGCCAGTCCGCCAAAGTTTA \\
IL-10 & NM_012854.2 & TTGAACCACCCGGCATCTAC & CCAAGGAGTTGCTCCCGTTA \\
Inos & XM_006246949.3 & CAGCCCTCAGAGTACAACGAT & CAGCAGGCACACGCAATGAT \\
SOD & X05634.1 & CGAGCATGGGTTCCATGTC & CTGGACCGCCATGTTTCTTAG \\
IL-1b & NM_031512.2 & GACTTCACCATGGAACCCGT & GGAGACTGCCCATTCTCGAC \\
p53 & NG_005120.4 & CTACTAAGGTCGTGAGACGCTGCC & TCAGCATACAGGTTCCTTCCACC \\
Nrf2 & NM_031789.1 & CAGGTTGCCCACATTCCCAA & ATATCCAGGGCAAGCGACTCAT \\
Bax & U49729.1 & CGCGTGGTTGCCCTCTTCTACTTT & CAAGCAGCCGCTCACGGAGGA \\
Bcl-2 & NM_016993.1 & ATCGCTCTGTGGATGACTGAGTAC & AGAGACAGCCAGGAGAAATCAAAC \\
GPx & NM_030826.4 & GGAGAATGGCAAGAATGAAGA & CCGCAGGAAGGTAAAGAG \\
TNF-a & NM_012675.3 & ACTGAACTTCGGGGTGATCG & GCTTGGTGGTTTGCTACGAC \\
NF-kB(p65) & NM_199267.2 & CGCGGGGACTATGACTTGAA & 106 \\
Caspase-9 & NM_031632 & CTGAGCCAGATGCTGTCCCATA & CCAAGGTCTCGATGTACCAGGAA \\
GAPDH & NM_017008 & TCACCACCATGGAGAAGGC & GCTAAGCAGTTGGTGGTGCA \\
Caspase-3 & NM_012922 & AAGATACCAGTGGAGGCCGACTTC & GGGAGAAGGACTCAAATTCCGTGG \\
\hline
\end{tabular}

CAT: catalase; iNOS; inducible nitric oxide synthase; SOD: superoxide dismutase; IL: interleukin; p53: tumour suppressor; Nrf2: nuclear factor erythroid 2-related factor 2; Bcl2: B-cell lymphoma 2; Bax: Bcl-2-associated X protein; GPx: glutathione peroxidase; TNF: tumour necrosis factor; NF-kB: nuclear factor kappa B; GAPDH: glyceraldehyde-3-phosphate dehydrogenase. 


\subsection{Immunohistochemistry Expression for PCNA, TNF- $\alpha, I L-1 \beta, I L-10$ and Cleaved Caspase-3}

Slides having $4 \mu \mathrm{m}$ thick testis sections attached to them were immersed in a pressure cooker filled with tris-EDTA buffer and 0.05\% tween $20(\mathrm{pH} \mathrm{9.0),} \mathrm{to} \mathrm{retrieve} \mathrm{antigens}$ for $3 \mathrm{~min}$. Thereafter, endogenous peroxidase was blocked using $3 \%$ hydrogen peroxide in phosphate buffered saline for $5 \mathrm{~min}$, followed by washing with distilled water and tris-buffered saline containing 0.05\% tween 20 (TBST, pH 8.4). Further, slide containing testis sections were incubated with polyclonal primary antibodies for PCNA (1:50), cleaved caspase-3 (1:150), NF-kB (p65) (1:80), IL-10 (1:40), IL-1 $\beta$ (1:80), and TNF- $\alpha(1: 120)$ (Cloud-Clone Corp, USA) for $24 \mathrm{~h}$ at $4{ }^{\circ} \mathrm{C}$. Testis sections were incubated with Dako EnVision $^{\mathrm{TM}}+$ System/HRP labelled polymer containing goat anti-rabbit secondary antibody (Agilent Technologies, Inc. United States of America) for $30 \mathrm{~min}$ at room temperature after washing with TBST. With the aid of Dako 3,3'-diaminobenzidine substrate (Agilent Technologies, Inc. USA) visualisation was conducted for $5 \mathrm{~min}$ at room temperature. Thereafter, hematoxylin was employed to counter stain the sections for $5 \mathrm{~s}$. They were dehydrated and viewed using a light microscope (Olympus BX41, United Kingdom). ImageJ software (ImageJ, NIH-Bethesda, MD, USA) was used to analyse the photographs for area and intensity of brown stain, and also to evaluate the quantitative data of the stained area.

\subsection{Statistical Analysis}

All data were analysed with the aid of GraphPad Prism version 7.0 (GraphPad Software Inc., La Jolla, CA, USA). All values were assessed for normality and homogenous variance using Shapiro-Wilk and D'Agostino-Pearson Omnibus normality tests. One-way analysis of variance (ANOVA) was employed for values with normal distribution, followed by Tukey post-hoc test. Values are shown as mean \pm standard deviation (SD). $p<0.05$ was considered statistically significant.

\section{Results}

\subsection{Body Weights and Weight Gain}

The $\mathrm{Ob}$ group revealed significant increases in the final body weight and weight gain relative to the $C$ group $(p<0.05)$. Meanwhile, the weight gain showed a significant decrease in the $\mathrm{Ob}+\mathrm{BB}$ group, but not in the $\mathrm{Ob}+\mathrm{OR}$ group relative to the Ob group $(p>0.05)$ (Table 2).

Table 2. Body weight and related parameters in all groups.

\begin{tabular}{ccccc}
\hline Parameter & $\mathbf{C}$ & $\mathbf{O b}$ & $\mathbf{O b}+\mathbf{B B}$ & Ob + OR \\
\hline Initial body weight & $242.20 \pm 34.47$ & $256.10 \pm 47.24$ & $271.90 \pm 14.14$ & $253.50 \pm 36.20$ \\
Final body weight $(\mathrm{g})$ & $386.80 \pm 40.11$ & $444.90 \pm 38.62^{\mathrm{a}}$ & $411.90 \pm 36.22$ & $405.30 \pm 41.25$ \\
Mean weight gain $(\mathrm{g})$ & $144.70 \pm 53.51$ & $188.90 \pm 44.80^{\mathrm{a}}$ & $140.10 \pm 32.46^{\mathrm{b}}$ & $151.80 \pm 19.18$ \\
Mean daily weight & $1.72 \pm 0.64$ & $2.25 \pm 0.53$ & $1.67 \pm 0.39$ & $1.81 \pm 0.23$ \\
gain (g/day) & & & & \\
\hline
\end{tabular}

C: normal control, Ob: obese rats, $\mathrm{Ob}+\mathrm{BB}$ : obese rat fed with high-fat diet plus bee bread (6 weeks), $\mathrm{Ob}+\mathrm{OR}$ : obese rat fed with high-fat diet plus orlistat (6 weeks). Data are shown as mean $\pm \mathrm{SD}, n=8 /$ group. ${ }^{\mathrm{a}} p<0.05$ vs. C, ${ }^{\mathrm{b}} p<0.05$ vs. Ob. (One-way ANOVA followed by Tukey post-hoc test).

\subsection{Energy Intake, Feed Consumption, Lee Obesity and Body Mass Index}

$\mathrm{BMI}$ and the Lee obesity index significantly increased in the Ob group relative to the $\mathrm{C}$ group $(p<0.05)$. Bee bread and orlistat treatment in the $\mathrm{Ob}+\mathrm{BB}$ and $\mathrm{Ob}+\mathrm{OR}$ groups, respectively, showed significant decreases in the above parameters relative to the Ob group (Table 3). Further, energy intake was significantly increased in the $\mathrm{Ob}, \mathrm{Ob}+\mathrm{BB}$ and $\mathrm{Ob}+\mathrm{OR}$ groups relative to the $\mathrm{C}$ group $(p<0.05)$ (Table 3$)$. 
Table 3. Energy intake, feed consumption, Lee obesity index, and Body mass index in all groups.

\begin{tabular}{ccccc}
\hline Parameter & $\mathbf{C}$ & Ob & Ob + BB & Ob + OR \\
\hline Lee obesity index & $305.90 \pm 5.88$ & $323.10 \pm 8.91^{\mathrm{a}}$ & $304.60 \pm 8.12^{\mathrm{b}}$ & $309.10 \pm 6.01^{\mathrm{b}}$ \\
BMI $\left(\mathrm{gcm}^{-1}\right.$ ) & $0.71 \pm 0.04$ & $0.83 \pm 0.06^{\mathrm{a}}$ & $0.72 \pm 0.04^{\mathrm{b}}$ & $0.73 \pm 0.05^{\mathrm{b}}$ \\
Total feed consumption (g) & $1822.00 \pm 125.80$ & $1647.00 \pm 266.20$ & $1560.00 \pm 171.40$ & $1628.00 \pm 232.80$ \\
Mean food consumption (g) & $21.69 \pm 1.49$ & $19.61 \pm 3.17$ & $18.57 \pm 2.04$ & $19.38 \pm 2.77$ \\
Energy intake (kcal/day) & $69.15 \pm 4.77$ & $101.30 \pm 16.37^{\mathrm{a}}$ & $95.91 \pm 10.53^{\mathrm{a}}$ & $100.10 \pm 14.31^{\mathrm{a}}$ \\
\hline
\end{tabular}

BMI: body mass index, C: normal control, Ob: obese rats, Ob + BB: obese rat fed with high-fat diet plus bee bread (6 weeks), $\mathrm{Ob}+\mathrm{OR}$ : obese rat fed with high-fat diet plus orlistat (6 weeks). Data are shown as mean $\pm \mathrm{SD}$ $n=8$ /group. ${ }^{\mathrm{a}} p<0.05$ vs. C, ${ }^{\mathrm{b}} p<0.05$ vs. Ob (One-way ANOVA followed by Tukey post-hoc test).

\subsection{Effects of Bee Bread on Weight of Reproductive Organs and Epididymal Fat of Obese Rats}

In the $\mathrm{Ob}$ group, the absolute and relative weights of the testis decreased significantly relative to the $\mathrm{C}$ group (Table 4). Moreover, significant increases were observed in absolute and relative weights of epididymal fat in the Ob group relative to the $\mathrm{C}$ group. Treatment with bee bread also showed a significant decreased relative weight of epididymal fat in the $\mathrm{Ob}+\mathrm{BB}$ group relative to the $\mathrm{C}$ and $\mathrm{Ob}$ groups. However, there were no significant differences among groups in the relative weights of the prostate, seminal vesicle, epididymis, and penis (Table 4).

Table 4. Reproductive organs and epididymal fat weights in all groups.

\begin{tabular}{cccccc}
\hline Parameter & & $\mathbf{C}$ & $\mathbf{O b}$ & $\mathbf{O b}+\mathbf{B B}$ & $\mathbf{O b}+\mathbf{O R}$ \\
\hline Testis $\neq$ & AW $(\mathrm{g})$ & $3.75 \pm 0.26$ & $3.34 \pm 0.58^{\mathrm{a}}$ & $3.52 \pm 0.29$ & $3.57 \pm 0.57$ \\
& RW $(\%)$ & $1.00 \pm 0.09$ & $0.79 \pm 0.19^{\mathrm{a}}$ & $0.82 \pm 0.11$ & $0.76 \pm 0.17^{\mathrm{a}}$ \\
Epididymis $\neq$ & AW $(\mathrm{g})$ & $1.52 \pm 0.28$ & $1.32 \pm 0.29$ & $1.51 \pm 0.22$ & $1.44 \pm 1.17$ \\
& RW $(\%)$ & $0.40 \pm 0.07$ & $0.31 \pm 0.09$ & $0.35 \pm 0.05$ & $0.31 \pm 0.06^{\mathrm{a}}$ \\
Prostate & AW $(\mathrm{g})$ & $1.22 \pm 0.43$ & $1.52 \pm 0.98$ & $1.53 \pm 0.61$ & $1.68 \pm 0.40$ \\
& RW $(\%)$ & $0.31 \pm 0.11$ & $0.34 \pm 0.20$ & $0.34 \pm 0.12$ & $0.35 \pm 0.09$ \\
Seminal Vessicle & AW $(\mathrm{g})$ & $1.76 \pm 0.30$ & $1.97 \pm 0.57$ & $2.11 \pm 0.41$ & $2.00 \pm 0.52$ \\
Penis & RW (\%) & $0.47 \pm 0.08$ & $0.45 \pm 0.11$ & $0.48 \pm 0.06$ & $0.42 \pm 0.12$ \\
& AW (g) & $0.27 \pm 0.04$ & $0.24 \pm 0.03^{\mathrm{a}}$ & $0.27 \pm 0.05$ & $0.30 \pm 0.03^{\mathrm{b}}$ \\
Epididymal Fat & RW (\%) & $0.07 \pm 0.01$ & $0.06 \pm 0.01$ & $0.06 \pm 0.01$ & $0.06 \pm 0.01$ \\
& AW (g) & $3.77 \pm 1.33$ & $10.38 \pm 4.27^{\mathrm{a}}$ & $7.87 \pm 5.89^{\mathrm{b}}$ & $9.54 \pm 3.92^{\mathrm{a}}$ \\
& RW (\%) & $0.99 \pm 0.28$ & $2.33 \pm 0.74^{\mathrm{a}}$ & $1.74 \pm 1.08$ & $1.92 \pm 0.54$
\end{tabular}

$\mp$ Data are the combined weights of the paired organs. AW: absolute weight; RW: relative weight; C: normal control; Ob: obese rats; Ob + BB: obese rat fed with high-fat diet plus bee bread (6 weeks); Ob + OR: obese rat fed with high-fat diet plus orlistat (6 weeks). Data are shown as mean $\pm \mathrm{SD}, n=8 /$ group. ${ }^{a} p<0.05$ vs. C, ${ }^{\mathrm{b}} p<0.05$ vs. Ob (One-way ANOVA followed by Tukey post-hoc test).

\subsection{Effects of Bee Bread on Serum Lipid Profile of Obese Rats}

The levels of triglyceride, LDL-C, total cholesterol increased significantly in the $\mathrm{Ob}$ group relative to the $\mathrm{C}$ group $(p<0.05)$, and similarly, the $\mathrm{Ob}$ group revealed a significant decrease in HDL level relative to the $C$ group (Table 5). The bee bread-treated group showed significant amelioration in HDL-C and LDL-C levels relative to the Ob group $(p<0.05)$ (Table 5).

Table 5. Lipid profile parameters in all groups.

\begin{tabular}{ccccc}
\hline Parameter & $\mathbf{C}$ & $\mathbf{O b}$ & $\mathbf{O b}+\mathbf{B B}$ & Ob + OR \\
\hline TC (mmol/L) & $1.61 \pm 0.18$ & $2.36 \pm 0.76^{\mathrm{a}}$ & $1.89 \pm 0.20$ & $2.11 \pm 0.17$ \\
TG (mmol/L) & $0.50 \pm 0.07$ & $0.93 \pm 0.09^{\mathrm{a}}$ & $0.71 \pm 0.15$ & $0.93 \pm 0.28^{\mathrm{a}}$ \\
HDL-C (mmol/L) & $0.42 \pm 0.10$ & $0.22 \pm 0.15^{\mathrm{a}}$ & $0.40 \pm 0.04^{\mathrm{b}}$ & $0.37 \pm 0.09$ \\
LDL-C (mmol/L) & $0.63 \pm 0.05$ & $1.56 \pm 0.15^{\mathrm{a}}$ & $1.25 \pm 0.14^{\mathrm{a}, \mathrm{b}}$ & $1.35 \pm 0.21^{\mathrm{a}}$
\end{tabular}

TC: total cholesterol, TG: triglyceride, HDL: high-density lipoproteins, LDL: low-density lipoproteins, C: normal control, $\mathrm{Ob}$ : obese rats, $\mathrm{Ob}+\mathrm{BB}$ : obese rat fed with high-fat diet plus bee bread (6 weeks), Ob + OR: obese rat fed with high-fat diet plus orlistat (6 weeks). Data are shown as mean $\pm \mathrm{SD}, n=8 /$ group. ${ }^{\mathrm{a}} p<0.05$ vs. C, ${ }^{\mathrm{b}} p<0.05$ vs. Ob (One-way ANOVA followed by Tukey post-hoc test). 


\subsection{Effects of Bee Bread on Testicular Histology of Obese Rats}

The histological architecture of the testes revealed decreases in epithelial height and the diameter of seminiferous tubules, as well as the concentration of the sperm (red arrows) in the $\mathrm{Ob}$ group relative to the $\mathrm{C}$ group $(p<0.05)$ (black arrows) (Figure $1 \mathrm{a}-\mathrm{g})$. The administration of bee bread revealed marked improvements for these parameters in the $\mathrm{Ob}+\mathrm{BB}$ group which were comparable to the orlistat-treated group.

a
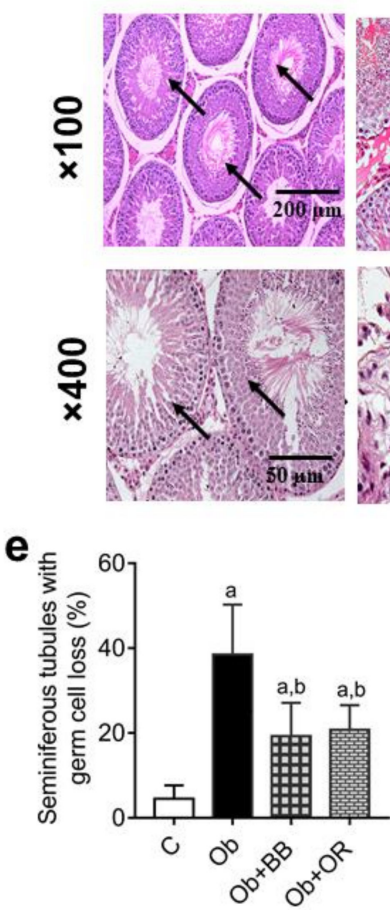

b
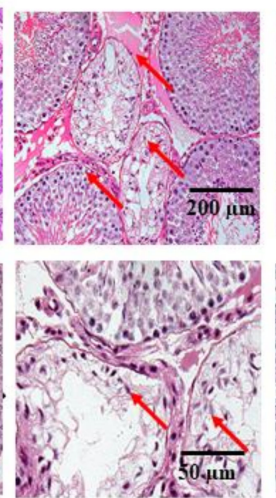

C
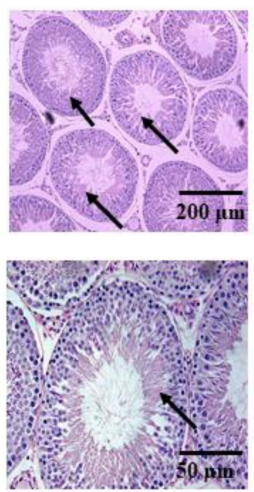

d
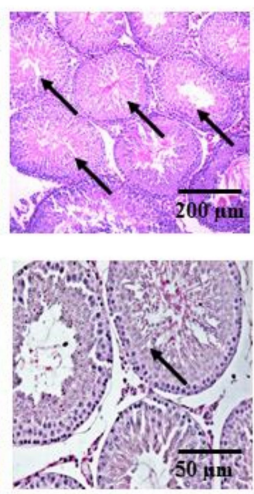

f

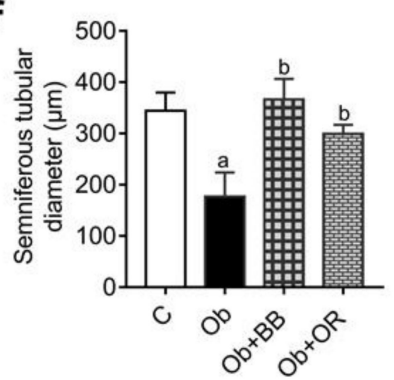

g

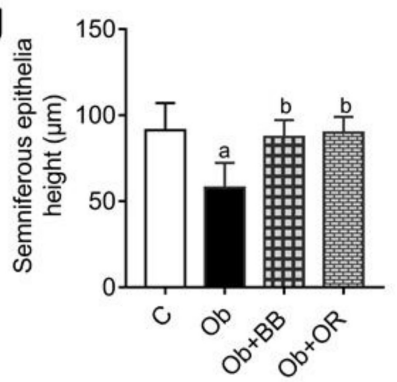

Figure 1. Representative photomicrographs of $\mathrm{H} \& \mathrm{E}$ staining of testes in (a) $\mathrm{C},(\mathbf{b}) \mathrm{Ob},(\mathbf{c}) \mathrm{Ob}+\mathrm{BB}$, (d) $\mathrm{Ob}+\mathrm{OR}$ groups. $\mathrm{C}$ : control; $\mathrm{Ob}$ : obese rats; $\mathrm{Ob}+\mathrm{BB}$ : obese + bee bread (6 weeks after induction of obesity); and $\mathrm{Ob}+\mathrm{OR}$ : obese + orlistat (6 weeks after induction of obesity). The seminiferous tubules in the $\mathrm{Ob}$ group were collapsed showing decreased amount of sperm and germ cells (red arrows) compared to $\mathrm{C}, \mathrm{Ob}+\mathrm{BB}$ and $\mathrm{Ob}+\mathrm{OR}$ groups $(\mathbf{c}, \mathbf{d})$ which showed increased amount of sperm and germ cells as well as normal size seminiferous tubules (black arrows) (magnification of panel above: $\times 100$, scale bar $=200 \mu \mathrm{m}$; magnification of panel below: $\times 400$, scale bar $=50 \mu \mathrm{m})$. (e) Seminiferous tubule with germ cell loss, (f) seminiferous tubular diameter, and (g) seminiferous epithelial height are quantitative data, values are mean $\pm \mathrm{SD}, n=6$. ${ }^{\mathrm{a}} p<0.05$ vs. $\mathrm{C},{ }^{\mathrm{b}} p<0.05$ vs. Ob (one-way ANOVA followed by Tukey post-hoc test).

Further, the Ob group revealed a significant increase in the percentage of seminiferous tubules with germ cell loss relative to the $C$ group. Nevertheless, there was a significant decrease in the percentage of seminiferous tubules with germ cell loss in the $\mathrm{Ob}+\mathrm{BB}$ group relative to the Ob group $(p<0.05)$, which was comparable to the $\mathrm{Ob}+\mathrm{OR}$ group (Figure 1e).

\subsection{Effects of Bee Bread on Testicular Oxidative Stress of Obese Rats}

The activities of SOD, CAT, GST, GPx and GR, as well as the TAC level, were significantly lower in the $\mathrm{Ob}$ group relative to the $\mathrm{C}$ group $(p<0.05)$. However, the administration of bee bread showed that these activities and the level in the $\mathrm{Ob}+\mathrm{BB}$ and $\mathrm{Ob}+\mathrm{OR}$ groups were increased significantly in the $\mathrm{Ob}+\mathrm{BB}$ group compared to the Ob group. In addition, the iNOS activity and MDA level were increased significantly in the Ob group relative to the $\mathrm{C}$ group. These were decreased significantly in the $\mathrm{Ob}+\mathrm{BB}$ and $\mathrm{Ob}+\mathrm{OR}$ groups (Table 6 ). 
Table 6. Oxidant-antioxidant Parameters in the testis in all groups.

\begin{tabular}{|c|c|c|c|c|}
\hline Parameters & $\mathrm{C}$ & $\mathrm{Ob}$ & $\mathrm{Ob}+\mathrm{BB}$ & $\mathrm{Ob}+\mathrm{OR}$ \\
\hline CAT activity (unit/mg protein) & $32.88 \pm 3.92$ & $14.86 \pm 3.29^{\mathrm{a}}$ & $25.80 \pm 3.11^{\mathrm{a}, \mathrm{b}}$ & $23.12 \pm 1.63^{a, b}$ \\
\hline GPx activity (unit/mg protein) & $43.60 \pm 2.19$ & $20.13 \pm 1.88^{a}$ & $41.30 \pm 3.14^{\mathrm{b}}$ & $37.79 \pm 1.80^{\mathrm{a}, \mathrm{b}, \mathrm{c}}$ \\
\hline GR activity (unit/mg protein) & $43.92 \pm 2.62$ & $16.99 \pm 1.79^{\mathrm{a}}$ & $46.71 \pm 6.53^{b}$ & $42.26 \pm 3.77^{b}$ \\
\hline GSH (mmol GSH Eq/mg protein) & $10.73 \pm 1.60$ & $19.76 \pm 5.41^{\mathrm{a}}$ & $13.94 \pm 2.38^{b}$ & $13.83 \pm 5.00^{b}$ \\
\hline GST activity (unit/mg protein) & $257.20 \pm 26.93$ & $151.40 \pm 17.32^{\mathrm{a}}$ & $272.2 \pm 24.37^{b}$ & $250.70 \pm 32.41^{b}$ \\
\hline iNOS activity (ng/mL protein) & $1.80 \pm 0.63$ & $7.31 \pm 1.06^{\mathrm{a}}$ & $3.01 \pm 0.79^{\mathrm{a}, \mathrm{b}}$ & $1.80 \pm 0.51^{b}$ \\
\hline MDA (nmol/mg protein) & $1.27 \pm 0.12$ & $12.01 \pm 0.76^{\mathrm{a}}$ & $1.70 \pm 0.28^{b}$ & $1.38 \pm 0.33^{b}$ \\
\hline SOD activity (unit/mg protein) & $2.78 \pm 0.12$ & $0.29 \pm 0.05^{\mathrm{a}}$ & $2.31 \pm 0.08^{b}$ & $2.31 \pm 0.09^{b}$ \\
\hline TAC (nmol uric acid Eq/mg protein) & $137.90 \pm 4.64$ & $63.64 \pm 6.01^{\mathrm{a}}$ & $131.30 \pm 10.85^{b}$ & $128.70 \pm 6.74^{b}$ \\
\hline
\end{tabular}

TAC: total antioxidant capacity, SOD: superoxide dismutase, MDA: malondialdehyde, GPx: glutathione peroxidase, GST: glutathione-S-transferase, GSH: total glutathione, CAT: catalase, GR: glutathione reductase, C: normal control, $\mathrm{Ob}$ : obese rats, $\mathrm{Ob}+\mathrm{BB}$ : obese rat fed with high-fat diet plus bee bread (6 weeks), Ob + OR: obese rat fed with high-fat diet plus orlistat (6 weeks). Data are presented as mean $\pm \mathrm{SD}, n=8 /$ group. ${ }^{\mathrm{a}} p<0.05 \mathrm{vs}$. C, ${ }^{\mathrm{b}} p<0.05$ vs. Ob, ${ }^{\mathrm{c}} p<0.05$ vs. Ob + BB (One-way ANOVA followed by Tukey post-hoc test).

\subsection{Effects of Bee Bread on mRNA Expressions of Testicular Oxidative Stress Markers of} Obese Rats

Gpx, Cat, Sod and Nrf2 mRNA transcript levels were decreased significantly in the $\mathrm{Ob}$ group relative to the $\mathrm{C}$ group. However, these genes, except for the Sod level, were significantly increased in the $\mathrm{Ob}+\mathrm{BB}$ and $\mathrm{Ob}+\mathrm{OR}$ groups relative to the $\mathrm{Ob}$ group (Figure 2).

a

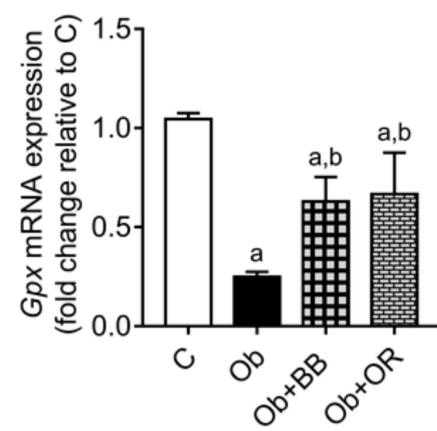

C

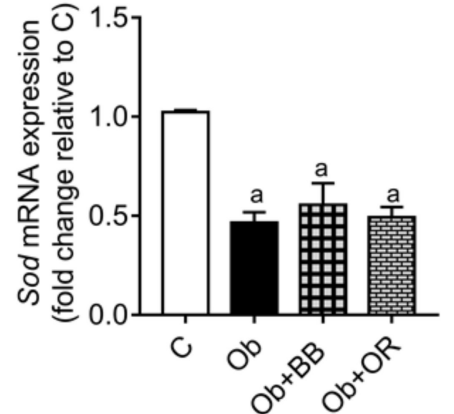

b

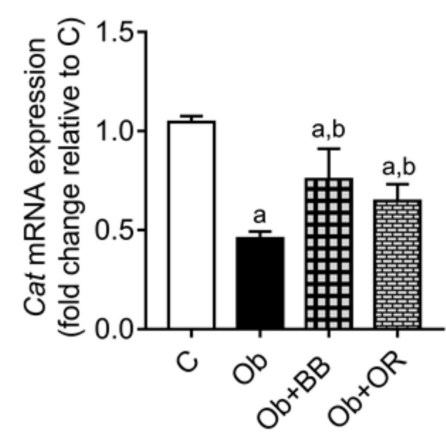

d

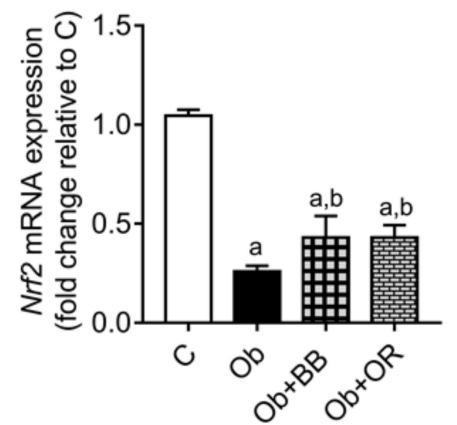

Figure 2. Effects of bee bread on the mRNA levels of oxidative stress markers; (a) Gpx, (b) Cat, (c) Sod, and (d) Nrf2 in the testes of obese rats. Gpx: glutathione peroxidase, Cat: catalase, Sod: superoxide dismutase, Nrf2: nuclear factor erythroid 2-related factor 2, C: control, Ob: obese rats, $\mathrm{Ob}+\mathrm{BB}$ : obese + bee bread ( 6 weeks after induction of obesity), and $\mathrm{Ob}+\mathrm{OR}$ : Obese + orlistat (6 weeks after induction of obesity). Values are shown mean $\pm \mathrm{SD}, n=6$. ${ }^{\mathrm{a}} p<0.05$ vs. $\mathrm{C},{ }^{\mathrm{b}} p<0.05$ vs. Ob (one-way ANOVA followed by Tukey's post-hoc test).

3.8. Effects of Bee Bread on mRNA and Protein Levels of Testicular Inflammation-Related Markers of Obese Rats

Tnf $-\alpha, N f-\kappa b(p 65), I l-1 \beta$ and Inos mRNA transcript levels increased significantly in the Ob group relative to the $C$ group $(p<0.05)$. Meanwhile, the mRNA transcript levels of 
these parameters decreased significantly in the $\mathrm{Ob}+\mathrm{BB}$ and $\mathrm{Ob}+\mathrm{OR}$ groups. Additionally, the Il-10 mRNA transcript level was decreased significantly in the Ob group relative to the C group $(p<0.05)$. Similarly, the Il-10 mRNA transcript level significantly increased in the $\mathrm{Ob}+\mathrm{BB}$ group relative to the $\mathrm{Ob}$ group (Figure $3 \mathrm{a}-\mathrm{e}$ ).

a

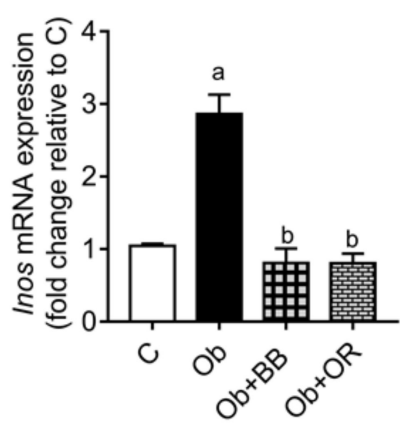

b

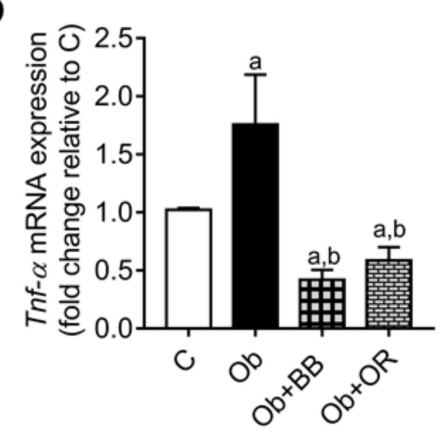

C

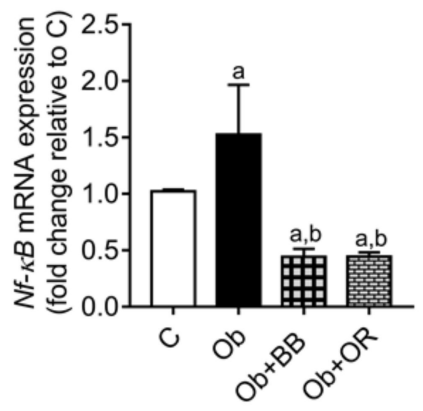

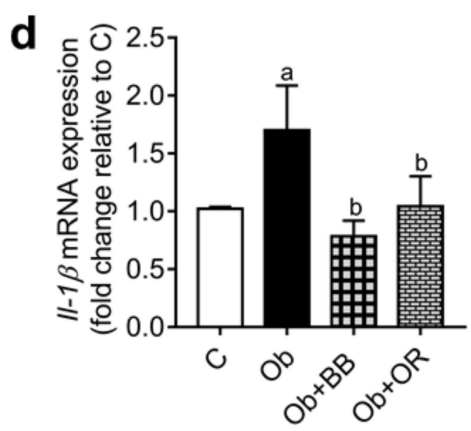

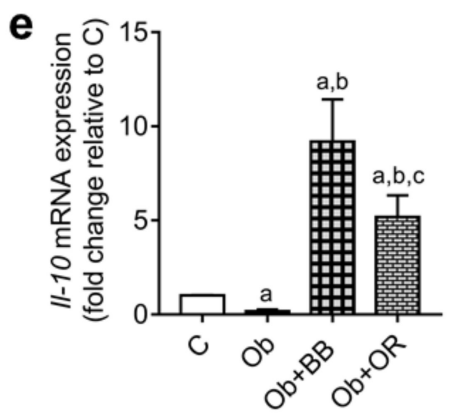

Figure 3. Effects of bee bread on the mRNA levels of inflammatory markers; (a) Inos, (b) Tnf- $\alpha$, (c) $N f-\kappa B$, (d) $I l-1 \beta$ and (e) $I l-10$ in the testes of obese rats. Inos: inducible nitric oxide synthase, Il: interleukin, $N f-\kappa B$ : nuclear factor kappa B, Tnf- $\alpha$ : tumour necrotic factor-alpha, C: control, Ob: obese rats, $\mathrm{Ob}+\mathrm{BB}$ : obese + bee bread ( 6 weeks after induction of obesity), and $\mathrm{Ob}+\mathrm{OR}$ : Obese + orlistat ( 6 weeks after induction of obesity). Values are mean $\pm \mathrm{SD}, n=6 .{ }^{\mathrm{a}} p<0.05 \mathrm{vs} . \mathrm{C},{ }^{\mathrm{b}} p<0.05 \mathrm{vs} . \mathrm{Ob}$, ${ }^{\mathrm{c}} p<0.05$ vs. $\mathrm{Ob}+\mathrm{BB}$ (one-way ANOVA followed by Tukey's post-hoc test).

Furthermore, the immunoexpression of the pro-inflammatory proteins TNF- $\alpha$, NF$\mathrm{kB}(\mathrm{p} 65)$, and IL-1ß were significantly increased in the testis of the Ob group relative to the $C$ group. Nevertheless, the above immunoexpressions decreased significantly in the $\mathrm{Ob}+\mathrm{BB}$ group relative to the $\mathrm{Ob}$ group $(p<0.05)$, which was comparable to the $\mathrm{Ob}+\mathrm{OR}$ group. On the other hand, the immunoexpression of the pro-inflammatory protein IL-10 was significantly decreased in the testis of the Ob group relative to the $\mathrm{C}$ group $(p<0.05)$. The administration of bee bread increased the immunoexpression of the IL-10 protein in the $\mathrm{Ob}+\mathrm{BB}$ group relative to the $\mathrm{Ob}$ group, comparable to the orlistat-treated groups. Image $\mathrm{J}$ software was used to analyse the quantitative data of the area stained in the images of IHC expression (Figure 4a-i). 

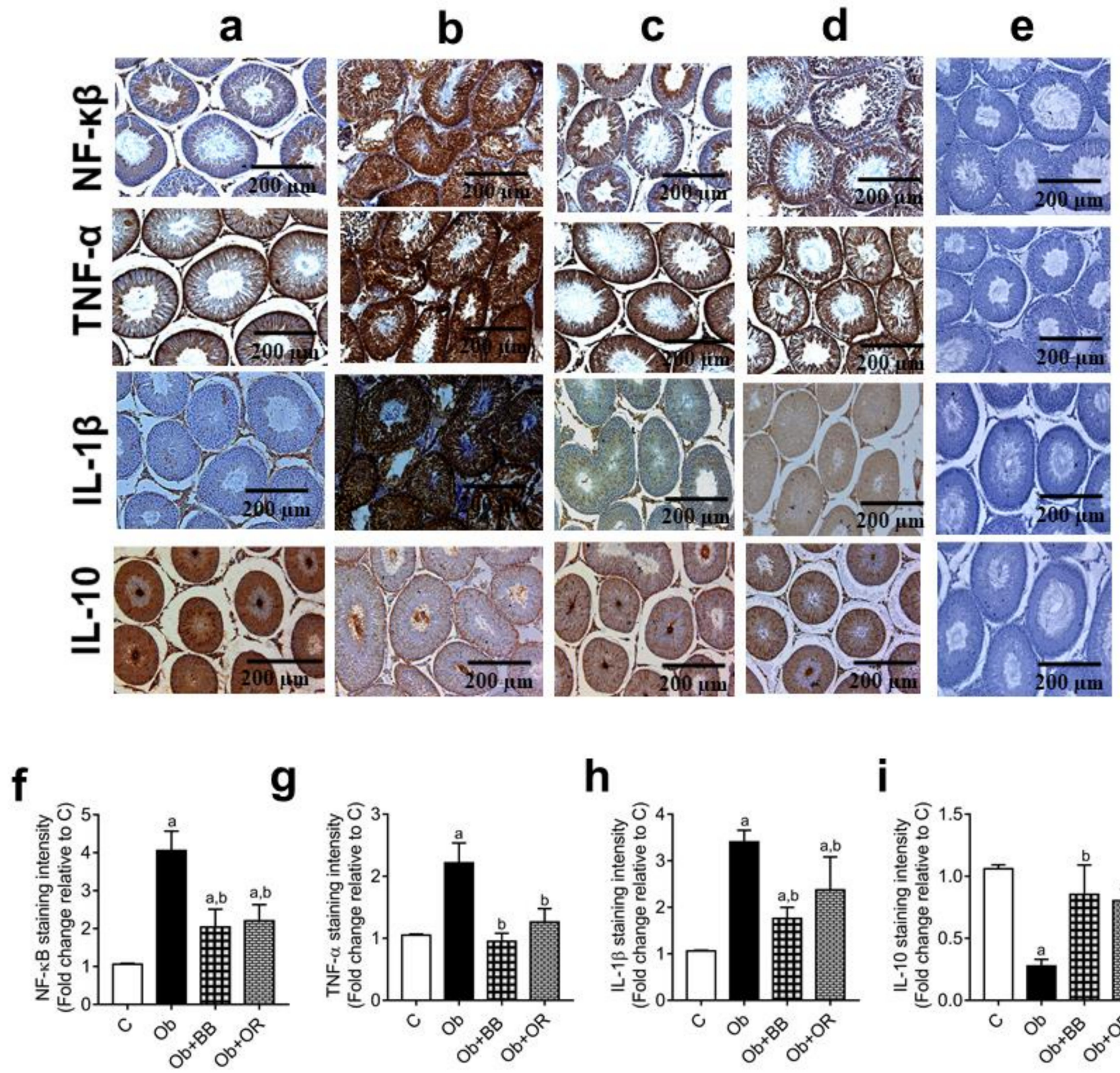

g

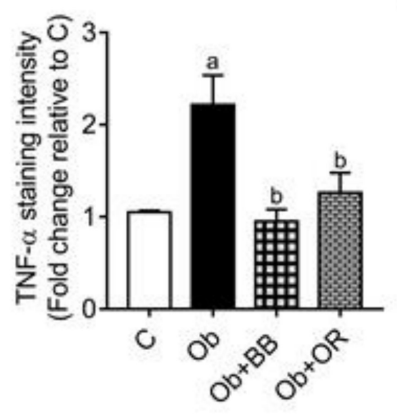

h

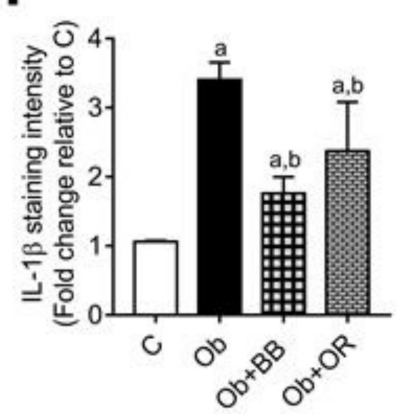

i

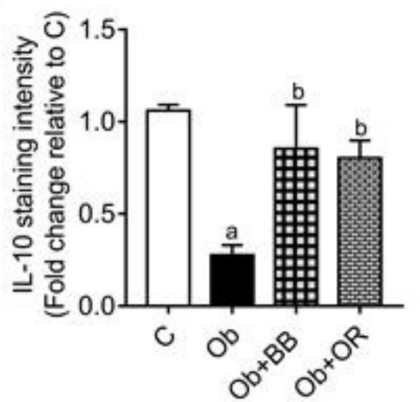

Figure 4. Effects of bee bread on immunoexpression of NF-kB, TNF- $\alpha$, IL-1 $\beta$ and IL-10 proteins in the testes of obese rats. For each protein, $\mathrm{C}, \mathrm{Ob}, \mathrm{Ob}+\mathrm{BB}$ and $\mathrm{Ob}+\mathrm{OR}$ groups are represented by (a-d), respectively, while (e) represents the negative control (PBS). Staining using immunohistochemistry protocol showed seminiferous tubules with increased expressions of NF- $\kappa B$, TNF- $\alpha$ and IL- $1 \beta$, and decreased expression of IL-10 in Ob group, compared to $\mathrm{C}, \mathrm{Ob}+\mathrm{BB}$ and $\mathrm{Ob}+\mathrm{OR}$ groups. Quantitative data are shown in (f) NF-kB, (g) TNF- $\alpha$, (h) IL-1 $\beta$ and (i) IL-10. Values are mean \pm SD, $n=6$. a $p<0.05$ vs. C, b $p<0.05$ vs. Ob (one-way ANOVA followed by Tukey's post-hoc test).

3.9. Effects of Bee Bread on mRNA and Protein Levels of Testicular Apoptosis-Related Markers and PCNA Expression of Obese Rats

Caspases-3, 8 and 9, Bax and p53 mRNA transcript levels were significantly increased in the $\mathrm{Ob}$ group relative to the $\mathrm{C}$ group. The mRNA levels of these parameters decreased significantly in the $\mathrm{Ob}+\mathrm{BB}$ group relative to the $\mathrm{Ob}$ group, which was comparable with the $\mathrm{Ob}+\mathrm{OR}$ group. Meanwhile, the $\mathrm{Bcl} 2 \mathrm{mRNA}$ level significantly decreased in the $\mathrm{Ob}$ group relative to the $\mathrm{C}$ group but increased significantly in the $\mathrm{Ob}+\mathrm{BB}$ group which was comparable with the $\mathrm{Ob}+\mathrm{OR}$ group. The $\mathrm{Bax} / \mathrm{Bcl} 2$ ratio increased significantly in the $\mathrm{Ob}$ 
group relative to the $\mathrm{C}$ group. A significant decrease in this ratio was observed in the $\mathrm{Ob}+$ $\mathrm{BB}$ group relative to the $\mathrm{Ob}$ group (Figure $5 \mathrm{a}-\mathrm{g}$ ).

a

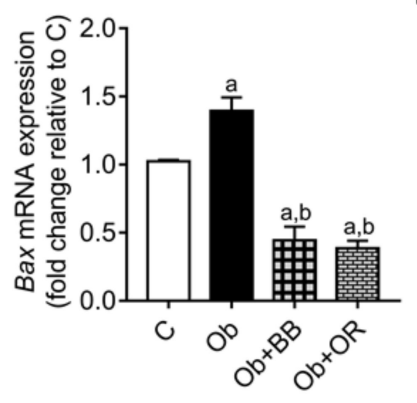

e

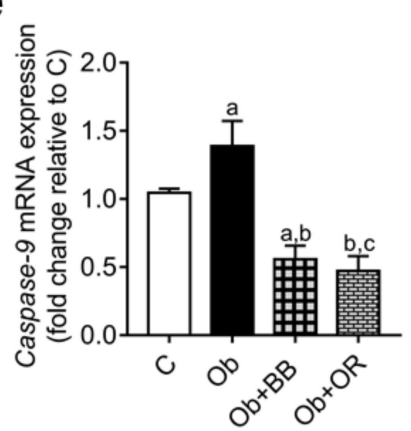

b

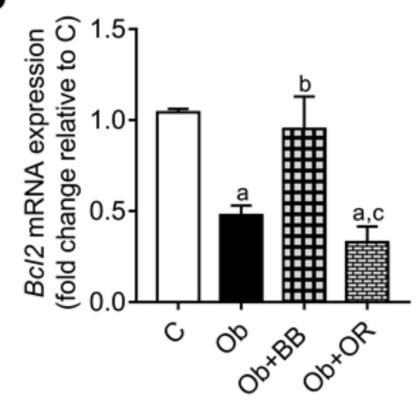

C

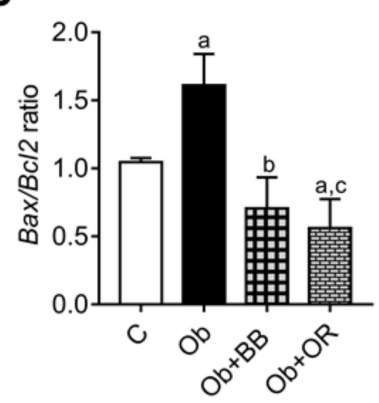

d

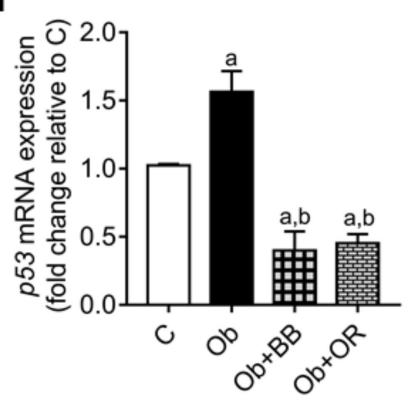

f
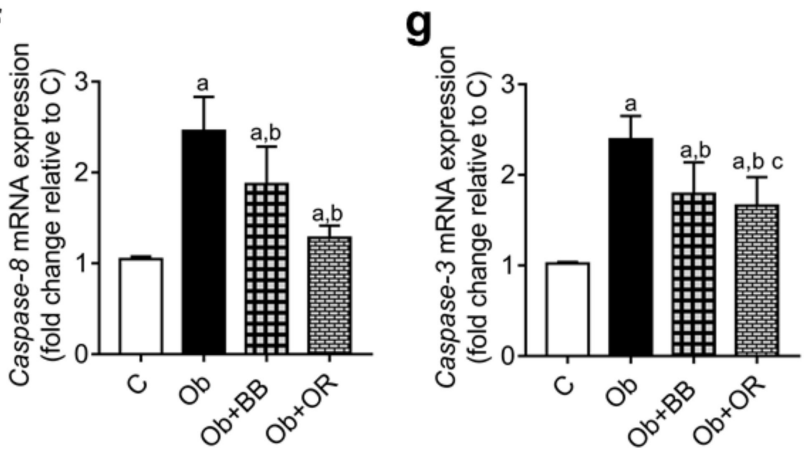

Figure 5. Effects of bee bread on the mRNA levels of apoptosis-related genes; (a) Bax, (b) Bcl-2, (c) Bax/Bcl2 ratio, (d) p53, (e) caspase-9, (f) caspase-8 and (g) caspase-3 in the testes of obese rats. p53: tumour suppressor, Bax: beta cell lymphoma 2 apoprotein $\mathrm{X}, \mathrm{Bcl} 2$ : beta cell lymphoma 2 . Values are mean $\pm \mathrm{SD}, n=6{ }^{\mathrm{a}} p<0.05$ vs. $\mathrm{C},{ }^{\mathrm{b}} p<0.05$ vs. $\mathrm{Ob},{ }^{\mathrm{c}} p<0.05$ vs. Ob $+\mathrm{BB}$ (one-way ANOVA followed by Tukey's post-hoc test).

The immunoexpression of PCNA positive germ cells was significantly decreased, and the immunoexpression of Caspase-3 was significantly increased in testis of the Ob group relative to the $C$ group. There were significant increases in the immunoexpressions of PCNA positive germ cells and significant decreases in the immunoexpressions of Caspase-3 in the $\mathrm{Ob}+\mathrm{BB}$ groups relative to the $\mathrm{Ob}$ group, which were comparable with orlistat-treated group (Figure 6a-g). 


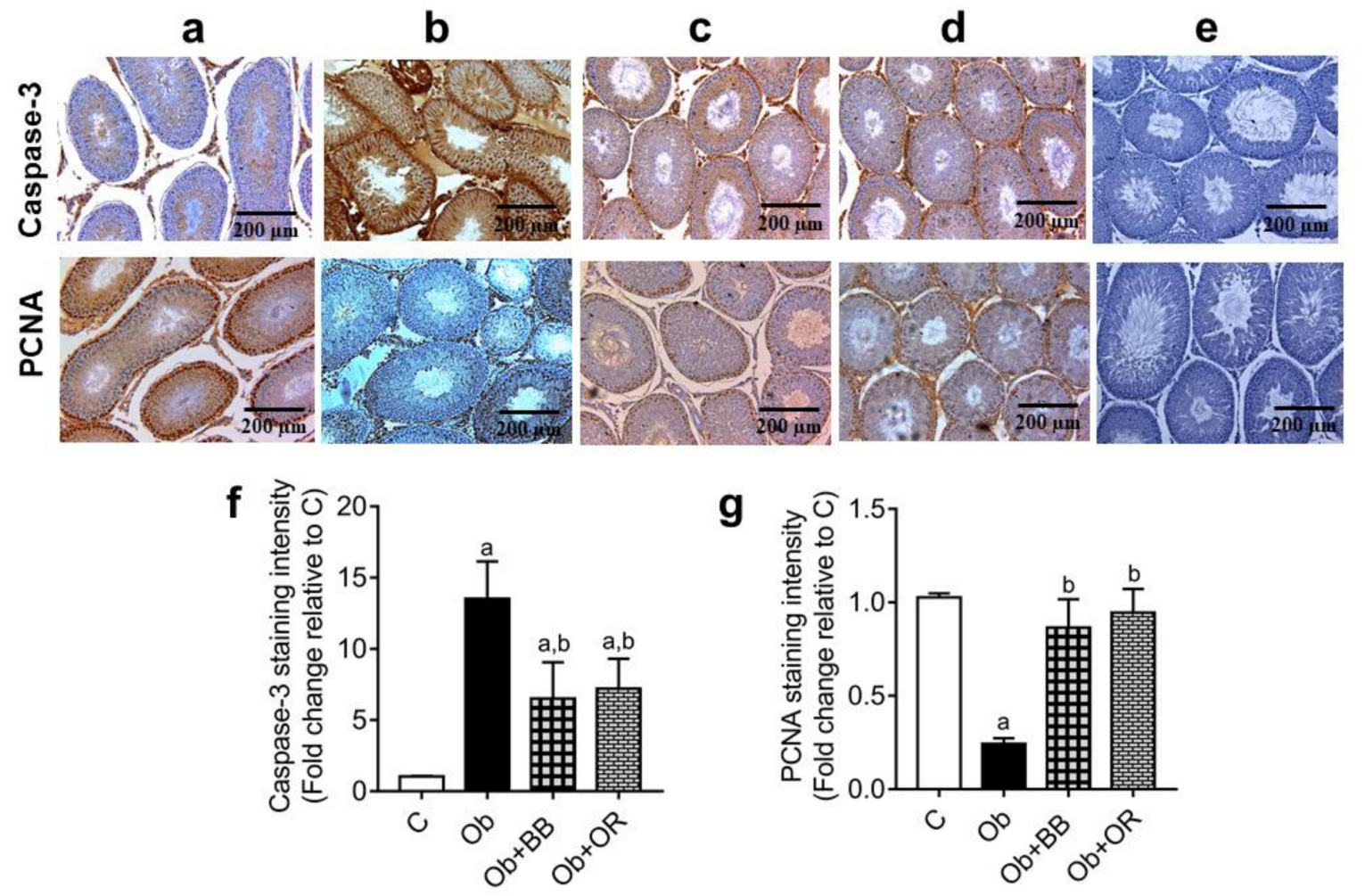

Figure 6. Effects of bee bread on immunoexpression of cleaved caspase-3 protein and proliferating cell nuclear antigen (PCNA) in the testes of obese rats. For each protein, $\mathrm{C}, \mathrm{Ob}, \mathrm{Ob}+\mathrm{BB}$, and $\mathrm{Ob}+\mathrm{OR}$ groups are represented by $(\mathbf{a}-\mathbf{d})$, respectively, while (e) represents the negative control (PBS). Staining using immunohistochemistry protocol showed seminiferous tubules with increased cleaved caspase- 3 and decreased PCNA levels in Ob group compared to $\mathrm{C}, \mathrm{Ob}+\mathrm{BB}$, and $\mathrm{Ob}+\mathrm{OR}$ groups $($ magnification $=\times 100$, scale bar $=200 \mu \mathrm{m}$ ). Quantitative data are shown in $(\mathbf{f})$ Caspase- 3 staining intensity, and (g) PCNA-positive germ cells. Values are mean $\pm \mathrm{SD}, n=6 .{ }^{\mathrm{a}} p<0.05$ vs. C, $\mathrm{b} p<0.05$ vs. Ob (one-way ANOVA followed by Tukey's post-hoc test).

\section{Discussion}

Infertility in males is fast becoming the sole factor responsible for about $20 \%$ of fertility problems in couples all over the world [29]. This may be as a result of several causes including metabolic diseases such as obesity. Obesity is a debilitating metabolic disease that affects most of the major organs of the body. One of such organs severely affected is the testis [30]. We had previously reported that increased consumption of HFD causes excessive testicular oxidative stress, high levels of inflammation, and apoptosis in obese rat models fed with HFD for twelve weeks [12,31]. Consequently, the administration of bee bread for the same period prevented, to a large extent, the development of obesity, as well as considerable decreases in the above parameters, thereby establishing the ameliorative/preventive effect of bee bread [12]. This present study, however, concentrated on the therapeutic effects of bee bread in obese male rats fed with HFD. The rat model was designed to first induce obesity in rats for 6 weeks and, subsequently, they were administered with bee bread for another 6 weeks after the confirmation of obesity. The reason for the model was to determine if bee bread could reverse the debilitating effects of obesity in the testis, in which the oxidative stress, inflammation and apoptotic parameters were also assessed.

Our study revealed increases in final body weight, mean weight gain and daily weight gain in the obese rats which corroborates with our previous finding [12,31]. Upon treatment with bee bread, reduction in weight again was observed, indicating that bee bread might suppress the lipogenic effect of HFD which results in the accumulation of fats leading to 
increase in weight gain. Furthermore, this lipogenic effects may be due to presence of phenols and flavonoids present in bee bread [3].

Consequently, increases in the body mass index, Lee obesity index, and energy intake in the obese rats were observed in our present study. This may be as a result of increased fats deposits in the adipocytes and corroborates with the findings of our previous model of inducing obesity $[12,31]$. However, treatment with bee bread revealed decreases in the body mass and Lee obesity indexes in the bee bread-treated group, for the present model of inducing obesity, and is consistent with our previously reported study which could be traced to the presence of phenols and flavonoids in bee bread [3].

Further, HFD-induced obesity caused an increased accumulation of lipids in adipose tissue, as indicated by the data from the increased weight of the epididymal fat in our present study which might be related to triglyceride accumulation in adipocytes that seems to be a major source of oxidative stress in white adipose tissues and adipocytokine dysregulation, leading to metabolic syndrome. Our study also revealed altered levels of TG, TC, LDL-C and HDL-C in the obese rats. Treatment with bee bread improved these parameters in the bee bread-treated rats and corroborates with our previous findings [12,31], which may be due to high amounts of phenols and flavonoid present in bee bread [3].

Oxidative stress is one of the mechanisms involved in obesity where several organs in the body, including the male reproductive organs like the testis and epididymis, are badly affected. Oxidative stress is referred to as an increase in the rate of cellular damage caused by oxygen and oxygen-derived oxidants known as radical oxygen species (ROS). It is important to state that the main targets of ROS are the membrane lipids causing lipid peroxidation. Thus, during spermatogenesis and spermiogenesis, sperm cells are readily attacked by the ROS leading to lipid peroxidation. HFD has been implicated in oxidative stress in the testis as our studies $[12,31]$ had earlier established that intake of HFD for 12 weeks induced testicular oxidative stress in male rats. Our present study also revealed increased testicular oxidative stress in the obese group which is in line with our previous study $[12,31]$. However, treatment with bee bread in the bee bread-treated group showed improvements in the oxidative status which may be due to the presence of active components like phenols and flavonoids, as well as some antioxidant properties found in bee bread [3].

Another very vital mechanism involved in the testis of obese males is inflammation. It is considered as an imbalance between the pro- and anti- inflammatory markers [49]. Previously, a group of cytokines were thought to be released during injuries and inflammation, especially by the immune system, but now they are known to actively regulate the immune system and inflammation [50]. In the male reproductive system, it is believed that cytokines, whose origin are from Sertoli cells, Leydig cells, seminal vesicles, the epididymis, prostate, testicular macrophages, and male accessory glands, accumulate in the seminal plasma, which ultimately affects steroidogenesis, spermatogenesis, and sperm function [51,52]. Intercellular and vascular adhesion molecules, as well as chemokines, are responsible for the secretion of necrotic fat cells which cause the proliferation and movement of monocytes and macrophages to adipose tissues [53,54].

Furthermore, pro-inflammatory markers are secreted by M1 macrophages, and activated by the NF- $\mathrm{kB}$ pathway, thereby increasing the release of pro-inflammatory markers, like interleukin-1 $\beta$ (IL-1 $\beta$ ), interleukin-6 (IL-6), and TNF- $\alpha$, as well as decreasing antiinflammatory markers [55]. The above events lead to chronic inflammation. In addition, an increase in the size of adipocytes results in local hypoxia due to inadequate blood flow. The cell increases the production of hypoxia inducible factor- $1 \alpha$ (HIF-1 $\alpha)$ [56], hemeoxygenesase-1 (HO-1) [57], pyruvate dehydrogenase kinase-1 (PDK1) and vascular endothelial growth factor (VEGF) [58] to protect itself against this hypoxic state. Our present study showed increased testicular inflammation in the obese group, which is consistent with our study previously reported [12,31]. Treatment with bee bread reversed this trend in the bee bread-treated group which is consistent with our previous model of inducing obesity and may be attributed to the presence of phenols and flavonoids [3]. 
Apoptosis is an organised cell death which helps in eliminating unwanted cells or damaged beyond repair [59]. The activation of Bcl-XL and Bax helps in maintaining the pro-apoptotic and anti-apoptotic markers [60,61]. Several studies have reported that one of the main causes of infertility in men is the imbalance between the pro- and anti-apoptotic factors [62,63]. In an obese state, the expression of Bcl-2 is suppressed, while that of Bax is significantly increased which leads to the caspase pathway activation [64]. Moreover, an increased level of lipids results in an increased level of stress which induces apoptosis in sperm cells with the increased expression of the binding immunoglobulin protein [65]. Our present study revealed increased testicular apoptosis in the obese group, which is consistent with our previous study [12,31]. However, treatment with bee bread in the bee bread-treated group caused reversal in apoptosis, suggesting an anti-apototic property of bee bread which may be due to the presence of active components like phenols and flavonoids in bee bread [3]. Therefore, the therapeutic effects of bee bread on testicularderived oxidative stress, inflammation and apoptosis are summarised in Figure 7.

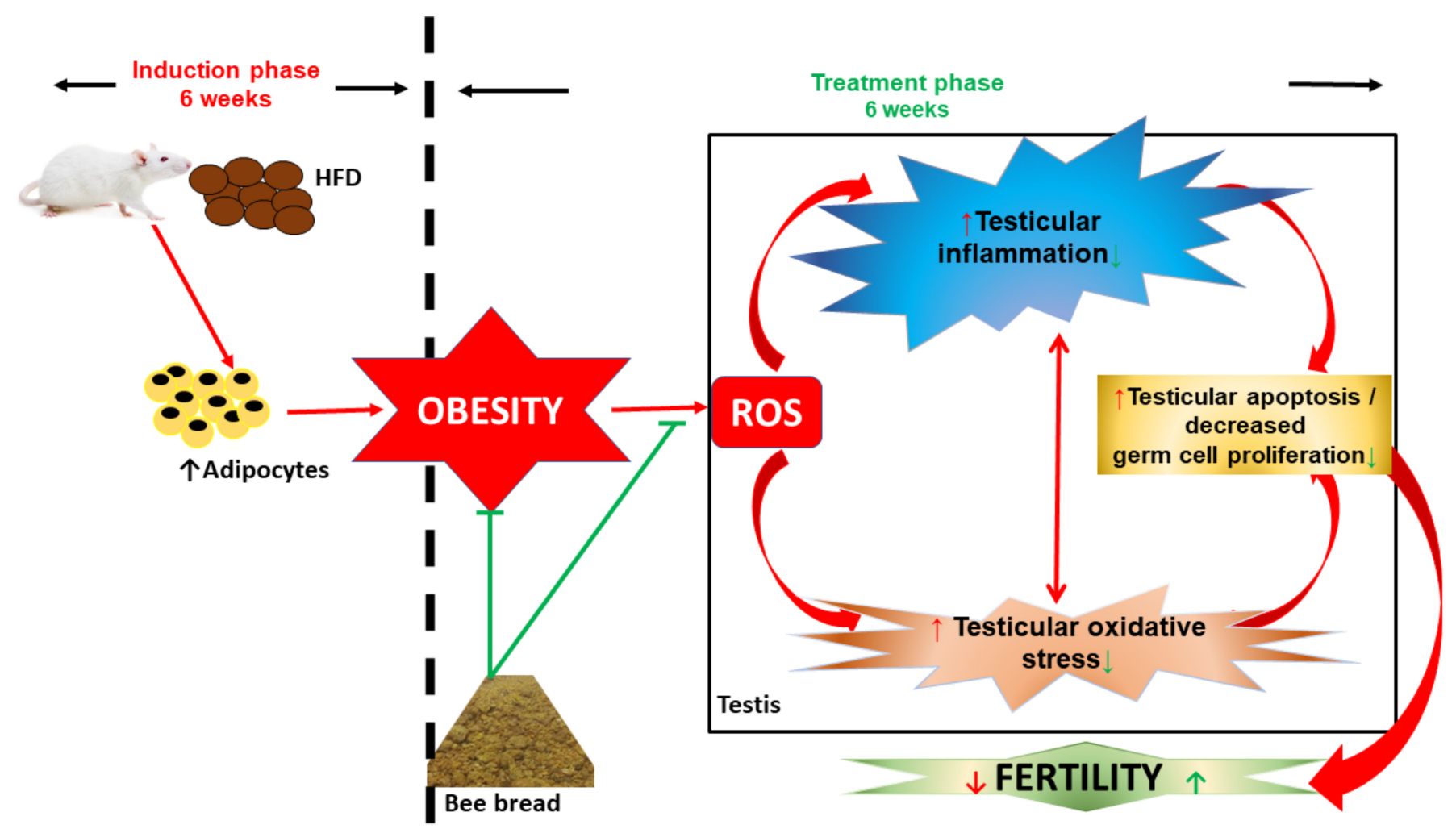

Figure 7. Schematic representation of therapeutic effects of bee bread on testicular-derived oxidative stress, inflammation, and apoptosis. HFD: high-fat diet, ROS reactive oxygen species.

\section{Conclusions}

Conclusively, our study has revealed that the consumption of HFD leads to obese conditions and poses a great danger to the body, including the male reproductive system. Secondly, it is now obvious that bee bread has therapeutic effects against oxidative stress, inflammation, and apoptosis generated by HFD in the testis in obese rats. This might partly be due to the presence of its constituents, which is suggested for further study to evaluate the exact molecular mechanism of action. Furthermore, a clinical trial is recommended to ascertain the use of bee bread for the possible treatment of infertility/sub-infertility in men with fertility problems. 


\begin{abstract}
Author Contributions: Conceptualization, M.M. and A.B.A.B.; methodology, J.B.S.; software, J.B.S.; validation, V.U.N., Z.A.O. and Z.Z.; formal analysis, J.B.S.; investigation, J.B.S., V.U.N., Z.A.O., A.B.A.B. and Z.Z.; writing—original draft preparation, J.B.S., V.U.N., Z.A.O., A.B.A.B. and Z.Z.; writing-review and editing, J.B.S., V.U.N., Z.A.O., A.B.A.B. and Z.Z.; visualization, J.B.S., and M.M.; supervision, M.M. and A.B.A.B.; project administration, M.M., and A.B.A.B.; funding acquisition, M.M. and A.B.A.B. All authors have read and agreed to the published version of the manuscript.
\end{abstract}

Funding: This study was financially supported by Universiti Sains Malaysia (USM) Malaysia (Grant number: 1001.PPSP.8012378).

Institutional Review Board Statement: Ethical approval (USM/IACUC/2018/(113)(933) was issued by USM Animal Ethics Committee. Instructions on animal handling and care were strictly followed according to the National Institute of Health.

Informed Consent Statement: Not applicable.

Data Availability Statement: All data is contained within the present article.

Acknowledgments: The authors hereby acknowledge the USM, Malaysia for funding this research and for giving the first author the USM Graduate Assistant Scheme Award.

Conflicts of Interest: The authors declare no conflict of interest.

\title{
References
}

1. Khalifa, S.A.; Elashal, M.; Kieliszek, M.; Ghazala, N.E.; Farag, M.A.; Saeed, A.; Xiao, J.; Zou, X.; Khatib, A.; Göransson, U. Recent insights into chemical and pharmacological studies of bee bread. Trends Food Sci. Technol. 2020, 97, 300-316. [CrossRef]

2. Kieliszek, M.; Piwowarek, K.; Kot, A.M.; Błażejak, S.; Chlebowska-Śmigiel, A.; Wolska, I. Pollen and bee bread as new healthoriented products: A review. Trends Food Sci. Technol. 2018, 71, 170-180. [CrossRef]

3. Suleiman, J.B.; Mohamed, M.; Abu Bakar, A.B.; Nna, V.U.; Zakaria, Z.; Othman, Z.A.; Aroyehun, A.B. Chemical Profile, Antioxidant Properties and Antimicrobial Activities of Malaysian Heterotrigona itama Bee Bread. Molecules 2021, $26,4943$. [CrossRef] [PubMed]

4. Mayda, N.; Özkök, A.; Bayram, N.E.; Gerçek, Y.C.; Sorkun, K. Bee bread and bee pollen of different plant sources: Determination of phenolic content, antioxidant activity, fatty acid and element profiles. J. Food Meas. Charact. 2020, 14, 1795-1809. [CrossRef]

5. Zuluaga, C.M.; Serrato, J.; Quicazan, M. Chemical, nutritional and bioactive characterization of Colombian bee-bread. Chem. Eng. 2015, 43, 175-180.

6. Mărgăoan, R.; Stranț, M.; Varadi, A.; Topal, E.; Yücel, B.; Cornea-Cipcigan, M.; Campos, M.G.; Vodnar, D.C. Bee collected pollen and bee bread: Bioactive constituents and health benefits. Antioxidants 2019, 8, 568. [CrossRef]

7. Suleiman, J.B.; Bakar, A.B.A.; Mohamed, M. Malaysian Bee Bread Attenuates Apoptosis and Improves Cell Proliferation in Testis of High-Fat Diet-Induced Obese Rats. Int. J. Hum. Health Sci 2019, 44, S44. [CrossRef]

8. Pełka, K.; Otłowska, O.; Worobo, R.W.; Szweda, P. Bee bread exhibits higher antimicrobial potential compared to bee pollen. Antibiotics 2021, 10, 125. [CrossRef]

9. $\quad$ Elsayed, N.; El-Din, H.S.; Altemimi, A.B.; Ahmed, H.Y.; Pratap-Singh, A.; Abedelmaksoud, T.G. In Vitro Antimicrobial, Antioxidant and Anticancer Activities of Egyptian Citrus Beebread. Molecules 2021, 26, 2433. [CrossRef]

10. Mărgăoan, R.; Cornea-Cipcigan, M.; Topal, E.; Kösoğlu, M. Impact of fermentation processes on the bioactive profile and health-promoting properties of bee bread, mead and honey vinegar. Processes 2020, 8, 1081. [CrossRef]

11. Martiniakova, M.; Blahova, J.; Kovacova, V.; Mondockova, V.; Babosova, R.; Kalafova, A.; Capcarova, M.; Omelka, R. Effects of bee bread, Cornelian cherries treatment on the femoral bone structure using Zucker diabetic fatty rats as an animal model. Veterinární Medicína 2021, 66, 342-349. [CrossRef]

12. Suleiman, J.B.; Nna, V.U.; Zakaria, Z.; Othman, Z.A.; Eleazu, C.O.; Bakar, A.B.A.; Ahmad, A.; Usman, U.Z.; Rahman, W.F.W.A.; Mohamed, M. Protective effects of bee bread on testicular oxidative stress, NF-kB-mediated inflammation, apoptosis and lactate transport decline in obese male rats. Biomed. Pharmacother. 2020, 131, 110781. [CrossRef] [PubMed]

13. Umer, A.; Kelley, G.A.; Cottrell, L.E.; Giacobbi, P.; Innes, K.E.; Lilly, C.L. Childhood obesity and adult cardiovascular disease risk factors: A systematic review with meta-analysis. BMC Public Health 2017, 17, 1-24. [CrossRef]

14. Blüher, M. Obesity: Global epidemiology and pathogenesis. Nat. Rev. Endocrinol. 2019, 15, 288-298. [CrossRef] [PubMed]

15. Suleiman, J.B.; Abu Bakar, A.; Mohamed, M. Review on effects of obesity on male reproductive system and the role of natural products. J. Appl. Pharm. Sci. 2019, 9, 131-141.

16. Morys, F.; García-García, I.; Dagher, A. Is obesity related to enhanced neural reactivity to visual food cues? A review and meta-analysis. Soc. Cogn. Affect. Neurosci. 2020, 14, 957-966. [CrossRef]

17. Song, R.-h.; Wang, B.; Yao, Q.-m.; Li, Q.; Jia, X.; Zhang, J.-a. The impact of obesity on thyroid autoimmunity and dysfunction: A systematic review and meta-analysis. Front. Immunol. 2019, 10, 2349. [CrossRef]

18. Othman, Z.A.; Zakaria, Z.; Suleiman, J.B.; Ghazali, W.S.W.; Mohamed, M. Anti-atherogenic effects of orlistat on obesity-induced vascular oxidative stress rat model. Antioxidants 2021, 10, 251. [CrossRef] 
19. Declèves, A.-E.; Sharma, K. Obesity and kidney disease: Differential effects of obesity on adipose tissue and kidney inflammation and fibrosis. Curr. Opin. Nephrol. Hypertens. 2015, 24, 28. [CrossRef]

20. Åberg, F.; Färkkilä, M. Drinking and obesity: Alcoholic liver disease/nonalcoholic fatty liver disease interactions. Semin. Liver Dis. 2020, 40, 154-162. [CrossRef]

21. Xu, M.; Jung, X.; Hines, O.J.; Eibl, G.; Chen, Y. Obesity and pancreatic cancer: Overview of epidemiology and potential prevention by weight loss. Pancreas 2018, 47, 158. [CrossRef] [PubMed]

22. Gotoh, K.; Fujiwara, K.; Anai, M.; Okamoto, M.; Masaki, T.; Kakuma, T.; Shibata, H. Role of spleen-derived IL-10 in prevention of systemic low-grade inflammation by obesity. Endocr. J. 2017, 64, 375-378. [CrossRef] [PubMed]

23. Tallis, J.; James, R.S.; Seebacher, F. The effects of obesity on skeletal muscle contractile function. J. Exp. Biol. 2018, 221, jeb163840. [CrossRef] [PubMed]

24. Fintini, D.; Cianfarani, S.; Cofini, M.; Andreoletti, A.; Ubertini, G.M.; Cappa, M.; Manco, M. The bones of children with obesity Front. Endocrinol. 2020, 11, 200. [CrossRef]

25. Gorbatenko, N.V.; Bezhenar, V.F.; Fishman, M.B. Obesity and reproductive health of women. Obes. Metab. 2017, 14, 3-8. [CrossRef]

26. Leisegang, K.; Henkel, R.; Agarwal, A. Obesity and metabolic syndrome associated with systemic inflammation and the impact on the male reproductive system. Am. J. Reprod. Immunol. 2019, 82, e13178. [CrossRef]

27. Ye, J.; Luo, D.; Xu, X.; Sun, M.; Su, X.; Tian, Z.; Zhang, M.; Yu, C.; Guan, Q. Metformin improves fertility in obese males by alleviating oxidative stress-induced blood-testis barrier damage. Oxid. Med. Cell. Longev. 2019, 2019, 9151067. [CrossRef]

28. Fariello, R.M.; de Carvalho, R.C.; Spaine, D.M.; Andretta, R.R.; Caetano, E.M.; Sa, G.P.; Cedenho, A.P.; Fraietta, R. Analysis of the Functional Aspects of Sperm and Testicular Oxidative Stress in Individuals Undergoing Metabolic Surgery. Obes. Surg. 2021, 31, 2887-2895. [CrossRef]

29. Yi, X.; Tang, D.; Cao, S.; Li, T.; Gao, H.; Ma, T.; Yao, T.; Li, J.; Chang, B. Effect of different exercise loads on testicular oxidative stress and reproductive function in obese male mice. Oxid. Med. Cell. Longev. 2020, 2020, 3071658. [CrossRef]

30. Erdemir, F.; Atilgan, D.; Markoc, F.; Boztepe, O.; Suha-Parlaktas, B.; Sahin, S. The effect of diet induced obesity on testicular tissue and serum oxidative stress parameters. Actas Urológicas Españolas 2012, 36, 153-159. [CrossRef]

31. Suleiman, J.B.; Nna, V.U.; Zakaria, Z.; Othman, Z.A.; Bakar, A.B.A.; Mohamed, M. Obesity-induced testicular oxidative stress, inflammation and apoptosis: Protective and therapeutic effects of orlistat. Reprod. Toxicol. 2020, 95, 113-122. [CrossRef] [PubMed]

32. El-Seedi, H.R.; Eid, N.; Abd El-Wahed, A.A.; Rateb, M.E.; Afifi, H.S.; Algethami, A.F.; Zhao, C.; Al Naggar, Y.; Alsharif, S.M.; Tahir, H.E. Honey Bee Products: Preclinical and Clinical Studies of Their Anti-inflammatory and Immunomodulatory Properties. Front. Nutr. 2022, 8, 761267. [CrossRef] [PubMed]

33. Nguyen, D.H.; Soygur, B.; Peng, S.-P.; Malki, S.; Hu, G.; Laird, D.J. Apoptosis in the fetal testis eliminates developmentally defective germ cell clones. Nat. Cell Biol. 2020, 22, 1423-1435. [CrossRef] [PubMed]

34. Wang, H.; Yuan, Q.; Niu, M.; Zhang, W.; Wen, L.; Fu, H.; Zhou, F.; He, Z. Transcriptional regulation of P63 on the apoptosis of male germ cells and three stages of spermatogenesis in mice. Cell Death Dis. 2018, 9, 1-16. [CrossRef]

35. Othman, Z.A.; Ghazali, W.; Syaheedah, W.; Noordin, L.; Yusof, M.; Aiman, N.; Mohamed, M. Phenolic Compounds and the Anti-Atherogenic Effect of Bee Bread in High-Fat Diet-Induced Obese Rats. Antioxidants 2020, 9, 33. [CrossRef]

36. Eleazu, C.; Suleiman, J.B.; Othman, Z.A.; Zakaria, Z.; Nna, V.U.; Mohamed, M. Effect of bee bread on some biochemical parameters and skeletal muscle histology of high-fat diet-induced obese Sprague-Dawley rats. J. Food Biochem. 2021, 45, e13626. [CrossRef]

37. Othman, Z.; Noordin, L.; Omar, N.; NA, M.Y.; Mohamaed, M. Protective Effects of Orlistat on Lipid Profile, Cardiac Oxidative Stress Biomarkers and Histology in High-fat Diet-induced Obese Rats. IIUM Med. J. Malays. 2019, 18. [CrossRef]

38. Eleazu, C.; Suleiman, J.B.; Othman, Z.A.; Zakaria, Z.; Nna, V.U.; Hussain, N.H.N.; Mohamed, M. Bee bread attenuates high fat diet induced renal pathology in obese rats via modulation of oxidative stress, downregulation of NF-kB mediated inflammation and Bax signalling. Arch. Physiol. Biochem. 2020, 1-17. [CrossRef]

39. Suleiman, J.B.; Nna, V.U.; Othman, Z.A.; Zakaria, Z.; Bakar, A.B.A.; Mohamed, M. Orlistat attenuates obesity-induced decline in steroidogenesis and spermatogenesis by up-regulating steroidogenic genes. Andrology 2020, 8, 1471-1485. [CrossRef] [PubMed]

40. Ohkawa, H.; Ohishi, N.; Yagi, K. Assay for lipid peroxides in animal tissues by thiobarbituric acid reaction. Anal. Biochem. 1979, 95, 351-358. [CrossRef]

41. Koracevic, D.; Koracevic, G.; Djordjevic, V.; Andrejevic, S.; Cosic, V. Method for the measurement of antioxidant activity in human fluids. J. Clin. Pathol. 2001, 54, 356-361. [CrossRef] [PubMed]

42. Sun, Y.; Oberley, L.W.; Li, Y. A simple method for clinical assay of superoxide dismutase. Clin. Chem. 1988, 34, 497-500. [CrossRef] [PubMed]

43. Goth, L. A simple method for determination of serum catalase activity and revision of reference range. Clin. Chim. Acta 1991, 196, 143-151. [CrossRef]

44. Paglia, D.E.; Valentine, W.N. Studies on the quantitative and qualitative characterization of erythrocyte glutathione peroxidase. J. Lab. Clin. Med. 1967, 70, 158-169.

45. Habig, W.H.; Pabst, M.J.; Jakoby, W.B. Glutathione S-transferases the first enzymatic step in mercapturic acid formation. J. Biol. Chem. 1974, 249, 7130-7139. [CrossRef]

46. Carlberg, I.; Mannervik, B. [59] Glutathione reductase. In Methods in Enzymology; Elsevier: Amsterdam, The Netherlands, 1985; Volume 113, pp. 484-490. 
47. Annuk, M.; Zilmer, M.; Lind, L.; Linde, T.; Fellström, B. Oxidative stress and endothelial function in chronic renal failure. J. Am. Soc. Nephrol. 2001, 12, 2747-2752. [CrossRef]

48. Livak, K.J.; Schmittgen, T.D. Analysis of relative gene expression data using real-time quantitative PCR and the $2-\Delta \Delta C T$ method Methods 2001, 25, 402-408. [CrossRef]

49. Rohm, I.; Atiskova, Y.; Drobnik, S.; Fritzenwanger, M.; Kretzschmar, D.; Pistulli, R.; Zanow, J.; Krönert, T.; Mall, G.; Figulla, H.R. Decreased regulatory $\mathrm{T}$ cells in vulnerable atherosclerotic lesions: Imbalance between pro-and anti-inflammatory cells in atherosclerosis. Mediat. Inflamm. 2015, 2015, 364710. [CrossRef]

50. Basar, M.M.; Avci, A.E. Obesity and Male Infertility: Energy Imbalance to Inflammation. Chem. Biol. Lett. 2021, 8, 162-170.

51. Henkel, R.; Offor, U.; Fisher, D. The role of infections and leukocytes in male infertility. Andrologia 2021, 53, e13743. [CrossRef]

52. Skosana, B.T. An Investigation of Obesity as an Etiology of Male Infertility in a Rat Model. Ph.D. Thesis, Stellenbosch University, Stellenbosch, South Africa, 2021.

53. Michicotl-Meneses, M.M.; Thompson-Bonilla, M.d.R.; Reyes-López, C.A.; García-Pérez, B.E.; López-Tenorio, I.I.; OrdazPichardo, C.; Jaramillo-Flores, M.E. Inflammation markers in adipose tissue and cardiovascular risk reduction by pomegranate juice in obesity induced by a hypercaloric diet in Wistar rats. Nutrients 2021, 13, 2577. [CrossRef] [PubMed]

54. Davanzo, G.G.; Hoffman, A.; Moraes-Vieira, P.M.M.d.; Becker, L. Adipose Tissue and Immuno-Metabolic Regulation. In Essential Aspects of Immunometabolism in Health and Disease; Springer: Berlin/Heidelberg, Germany, 2022; pp. $203-220$.

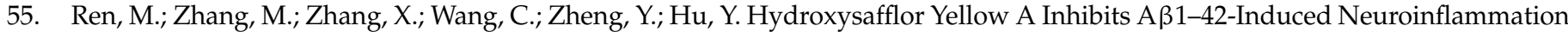
by Modulating the Phenotypic Transformation of Microglia via TREM2/TLR4/NF- $\mathrm{B}$ Pathway in BV-2 Cells. Neurochem. Res. 2021, 1-14. [CrossRef] [PubMed]

56. Feng, J.; Zhan, J.; Ma, S. LRG1 promotes hypoxia-induced cardiomyocyte apoptosis and autophagy by regulating Hypoxiainducible factor-1 $\alpha$. Bioengineered 2021, 8897-8907. [CrossRef] [PubMed]

57. Dunn, L.L.; Kong, S.M.; Tumanov, S.; Chen, W.; Cantley, J.; Ayer, A.; Maghzal, G.J.; Midwinter, R.G.; Chan, K.H.; Ng, M.K. Hmox1 (Heme Oxygenase-1) Protects Against Ischemia-Mediated Injury via Stabilization of HIF-1 $\alpha$ (Hypoxia-Inducible Factor- $1 \alpha$ ). Arterioscler. Thromb. Vasc. Biol. 2021, 41, 317-330. [CrossRef] [PubMed]

58. Kim, B.-S.; Chung, T.-W.; Choi, H.-J.; Bae, S.-J.; Cho, H.-R.; Lee, S.-O.; Choi, J.-H.; Joo, J.K.; Ha, K.-T. Caesalpinia sappan induces apoptotic cell death in ectopic endometrial $12 \mathrm{Z}$ cells through suppressing pyruvate dehydrogenase kinase 1 expression. Exp. Ther. Med. 2021, 21, 357. [CrossRef]

59. Das, S.; Shukla, N.; Singh, S.S.; Kushwaha, S.; Shrivastava, R. Mechanism of interaction between autophagy and apoptosis in cancer. Apoptosis 2021, 26, 512-533. [CrossRef]

60. Batool, Z.; Hu, G.; Huang, X.; Wu, Y.; Fu, X.; Cai, Z.; Huang, X.; Ma, M. Dietary therapeutic treatment of renal carcinoma cell lines by down-regulating cFlip, Mcl-1, Bcl-XL and STAT3 gene expression under the influence of up-regulated Bax and intrinsic apoptotic pathway. Food Biosci. 2021, 43, 101319. [CrossRef]

61. Vasquez-Montes, V.; Rodnin, M.V.; Kyrychenko, A.; Ladokhin, A.S. Lipids modulate the BH3-independent membrane targeting and activation of BAX and Bcl-xL. Proc. Natl. Acad. Sci. USA 2021, 118, e2025834118. [CrossRef]

62. Frungieri, M.B.; Calandra, R.S.; Bartke, A.; Matzkin, M.E. Male and female gonadal ageing: Its impact on health span and life span. Mech. Ageing Dev. 2021, 197, 111519. [CrossRef]

63. Amiri, G.; Gholami, M.; Assadollahi, V.; Nemati, A.; Fathi, F.; Rostami, T.; Moloudi, M.R.; Alasvand, M. Effect of Cerium Oxide Nanoparticles on the Expression of Developmental and Apoptosis Genes of Testicular Tissue in 6-Day-Old NMRI Mice Fetuses. Biol. Trace Elem. Res. 2021, 1-10. [CrossRef]

64. Dey, A.; Perveen, H.; Khandare, A.L.; Banerjee, A.; Maiti, S.; Jana, S.; Chakraborty, A.K.; Chattopadhyay, S. Arsenic-induced uterine apoptotic damage is protected by ethyl acetate fraction of Camellia sinensis (green tea) via Bcl-2-BAX through NF- $\mathrm{B}$ regulations in Wistar rats. Environ. Sci. Pollut. Res. 2021, 28, 41095-41108. [CrossRef] [PubMed]

65. Meenakshi, J.; Goswami, S.; Datta, K. Constitutive expression of hyaluronan binding protein 1 (HABP1/p32/gC1qR) in normal fibroblast cells perturbs its growth characteristics and induces apoptosis. Biochem. Biophys. Res. Commun. 2003, 300, 686-693. [CrossRef] 